\title{
Characteristics of seismic energy release of subduction zones-examples from Taiwan
}

\author{
F.S. Jeng ${ }^{\mathrm{a}, *}$, M.L. Lin ${ }^{\mathrm{a}}$, C.Y. Lu ${ }^{\mathrm{b}}$, K.P. Huang ${ }^{\mathrm{a}}$ \\ ${ }^{a}$ Department of Civil Engineering, National Taiwan University, 1, Sec. 4, Roosevelt Road, Taipei 106, Taiwan \\ ${ }^{\mathrm{b}}$ Department of Geological Sciences, National Taiwan University, Taipei 106, Taiwan
}

Received 4 September 2001; accepted 22 March 2002

\begin{abstract}
The characteristics of seismic energy releasing for oceanic subduction and continental collision or subduction zones were explored by a proposed observational approach based on contour maps of seismic energy release on both horizontal and vertical planes, magnitude-energy curve and magnitude-energy-time relationship. It was found that distinct features of energyreleasing behavior exist for the two types of subduction. The oceanic subduction tends to have a more active background noise by continuously emitting small magnitude earthquakes and to release energy from a wider range of depth owing to the existence of subducted plate. On the other hand, surficial strata of a continental subduction tend to release almost all of the seismic energy through a major earthquake with relatively much less long-term noise. Meanwhile, several seismic gaps have been found based on the proposed release energy contour. Together with the tectonic framework and the regional geologic setting, these gaps potentially may involve aseismic zones (e.g., accretionary deposit) or zones awaiting to release its accumulated energy (e.g., the upper crust). The quite zones prone to yielding major earthquakes are accordingly highlighted for a further study. (C) 2002 Elsevier Science B.V. All rights reserved.
\end{abstract}

Keywords: Seismic energy release; Seismic behavior of subduction zone; Seismicity of Taiwan; Seismic gap

\section{Introduction}

In an active seismic zone, the total amount of energy released is of interest. On the other hand, how this total amount of energy is released, e.g., whether in many small earthquakes or in a single, strong earthquake, is of great significance for human society and for engineering design and corresponding codes as well.

\footnotetext{
${ }^{*}$ Corresponding author. Tel.: +886-2-2363-0530; fax: +886-22363-1558.

E-mail address: fsjeng@ce.ntu.edu.tw (F.S. Jeng).
}

Taiwan is characterized with complex geological structures and frequent earthquakes, resulted from the oblique convergence of Philippine Sea plate toward the Eurasian plate at Taiwan (Angelier et al., 1986; Biq, 1989; Ho, 1986; Lallemand and Tsien, 1997; Lu and Malavieille, 1994; Lu et al., 1995; Suppe, 1984). Essentially, two types of subduction zones exist around Taiwan: two oceanic subduction zones around the northeastern and the southern Taiwan and one continental collision or subduction zone around the middle Taiwan (Lallemand, 2000). These two types of subduction zones exhibit distinct features of seismic energy releasing as will be presented in later section of this paper. 
On the other hand, two extensive networks of seismological monitoring stations have been setup to monitor the seismic energy releasing, and tremendous amount of seismological data have been recorded, especially over the past three decades (Wang and Shin, 1998).

Based on events occurred in the vicinity of Taiwan over the past three decades, this study aims to identify the energy-releasing characteristics of subduction zones with emphasis on the potentiality for the occurrence of large-magnitude earthquakes in the regions studied. To achieve this aim, an observational technique is accordingly proposed to examine the energyreleasing behavior of the regions studied.

\subsection{Geological setting of Taiwan}

The Taiwan mountain belt is located at the oblique convergent boundary of the Eurasian plate (EUP) and the Philippine Sea plate (PSP) as shown in Figs. 1 and 2. The PSP is mainly oceanic in nature, and the EUP is continental in general except that it also includes an oceanic crust in the abyssal part of the South China Sea (Lallemand, 2000; Lallemand et al., 2001). Furthermore, a third tectonic unit, the Peikang basement High (PKH), a continental part of EUP, exists in the mid-southern Taiwan as shown in Fig. 2. The neotectonic activity indicates that the southern foreland thrust belt of Taiwan (the Western Foothills) is impeded by this basement high, which not only results in $S$-shaped fault lines, but also induces significant earthquake events (Tang, 1977; Lu, 1994; Lu and Malavieille, 1994). This third unit is small in size compared to the first two tectonic units; however, it accounts for the occurrence of several devastating earthquakes in the Western Foothills and thus cautiously requires attention (Wang et al., 2000).

The Philippine Sea plate has subducted beneath the Eurasian plate along the Ryukyu trench and, meanwhile, has been overriding by the crust of the South China Sea along the Manila trench since late Cenozoic to the present (Angelier et al., 1986; Biq, 1989; Ho, 1986; Lallemand and Tsien, 1997; Lu and Malavieille, 1994; Lu et al., 1995; Suppe, 1984). The subduction of these plates results in the major geological units of Taiwan, from west to east, include: the Coastal Plain, the Western Foothills, the Hsuehshan Range, the Backbone Range, the Meso/Paleozoic Basement and the Coastal Range as shown in Fig. 2. The Luzon Arc collided with the Eurasian plate in early Pliocene and formed the Taiwan mountain belt through a series of uplifting, metamorphism, faulting and folding, re-

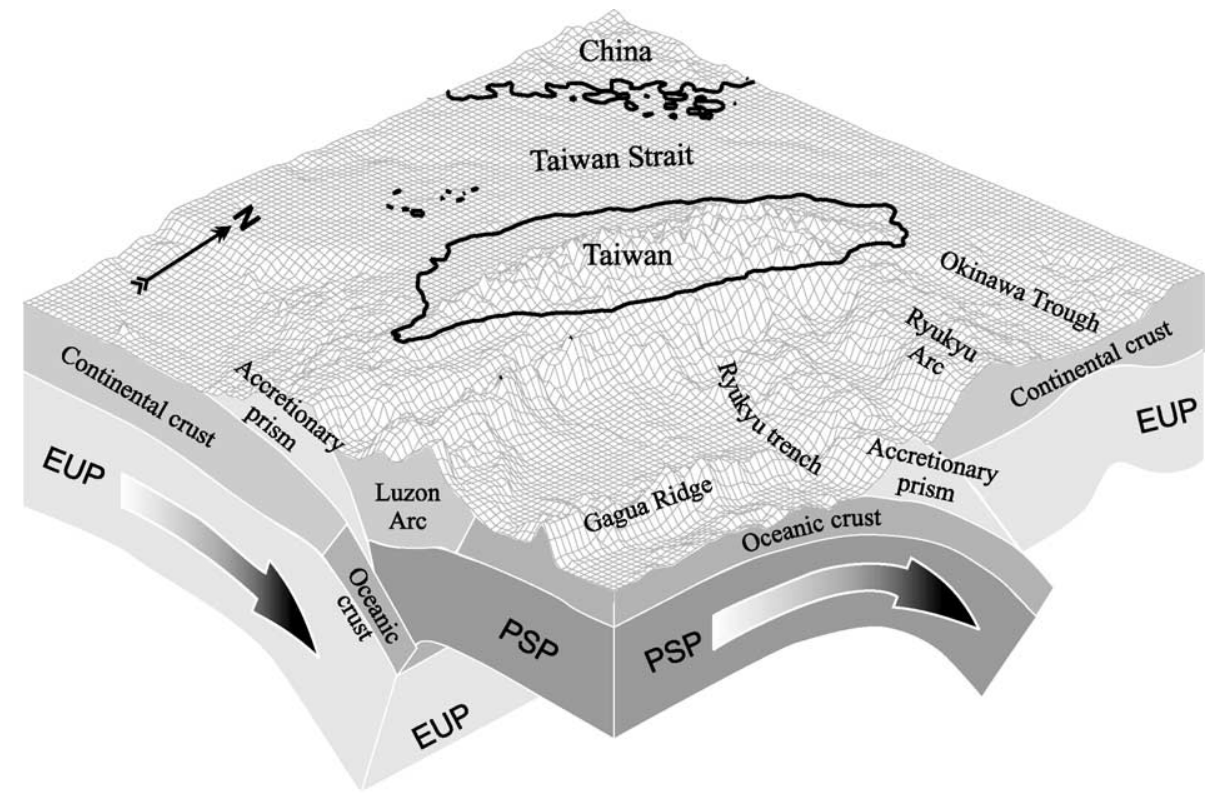

Fig. 1. Configuration of plate subduction around Taiwan (modified after Angelier et al., 1986). PSP=Philippine Sea plate; EUP=Eurasian plate. 


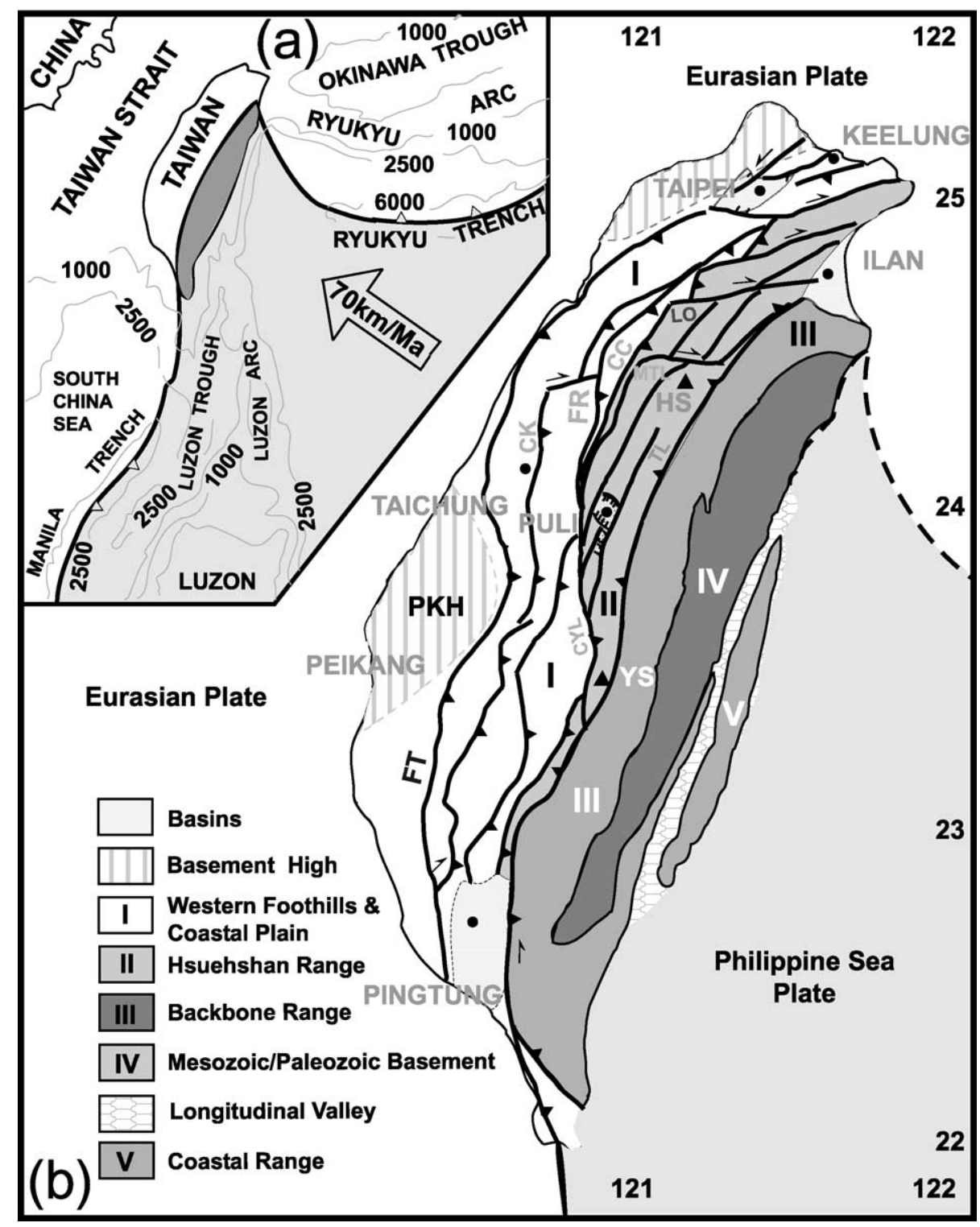

Fig. 2. Main stratigraphic units of Taiwan (modified after Ho, 1986; Biq, 1989; Lu and Malavieille, 1994). CC: Chiuchih Fault, CK: Chukou Fault, CYL: Chenyulanchi Fault, FR: Frontal Range Thrust, FT: Foothill Thrust, LO: Loshan Fault, LS: Lishan Fault, MTL: Matalanchi Fault, PKH: Peikang basement high; TL: Tili Fault; YS: Yushan, HS: Hsuehshan.

ferred to as the Penglai Orogeny of the Taiwan mountain belt. To date, being the major tectonic activity of the Taiwan mountain belt, the Philippine Sea plate still moves in the $\mathrm{N} 55^{\circ} \mathrm{W}$ direction, at the rate of $7 \mathrm{~cm} /$ year, and collides with the Eurasian continental margin (Seno, 1977). Numerical simulation of the plate convergence around Taiwan indicates that significant strain energy has been built up in the vicinity of Peikang basement High as shown in Fig. 3 (Jeng et al., 1996). The result of numerical analysis indicates that the impediment of the northwest movement of the surficial strata by the Peikang basement High accounts for such local concentration of strain energy. 


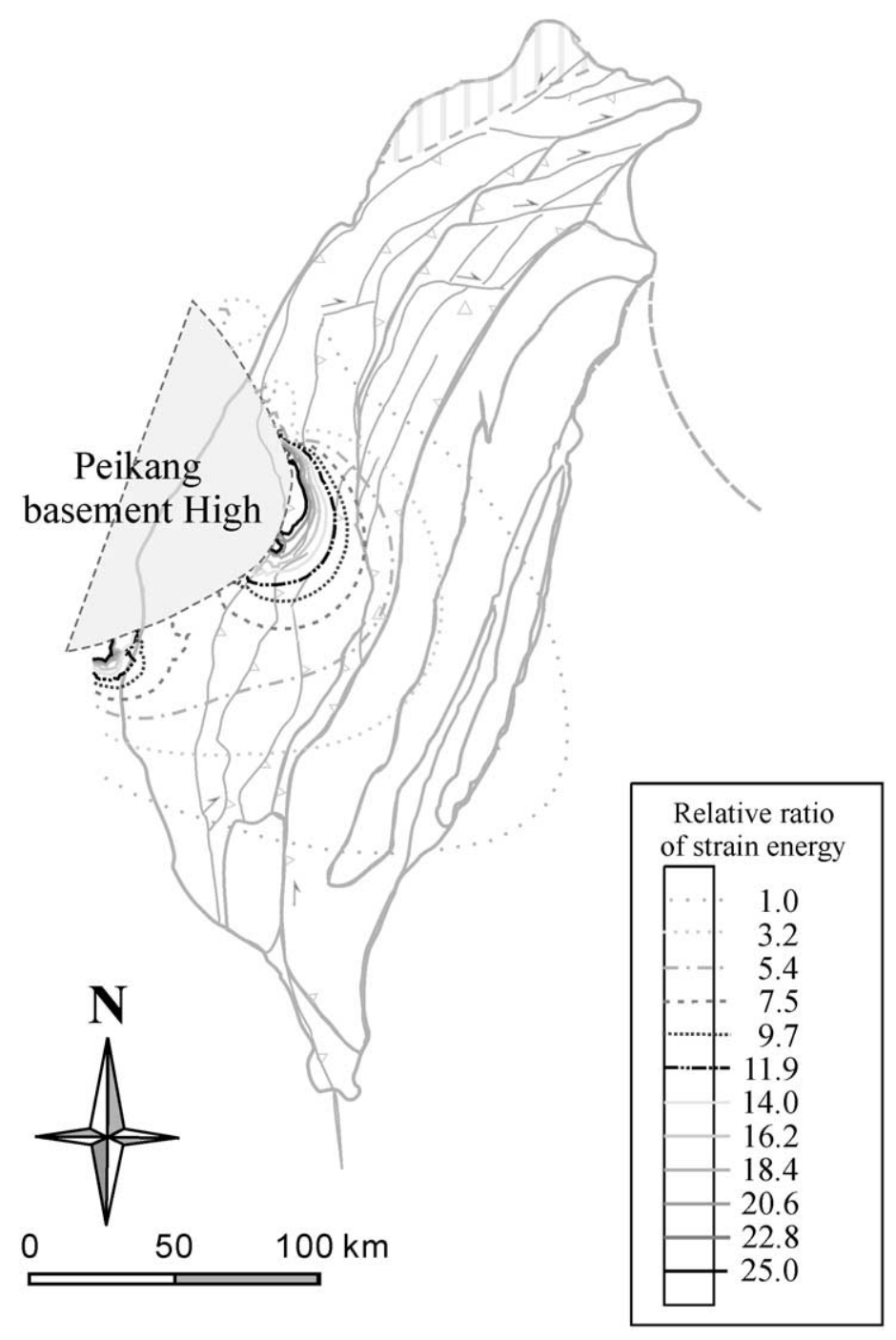

Fig. 3. Distribution of strain energy induced by impediment of Peikang basement High against oblique convergence (after Jeng et al., 1996). The induced strain energy is presented in terms of relative strain energy ratio, which is made by normalizing the strain energy of each contour with the magnitude of strain energy of the outmost contour.

\subsection{Earthquake background of Taiwan}

Given the frequent earthquake in Taiwan, an extensive network of seismic stations has been accordingly setup to monitor the release of energy. A total of 707 seismological stations, with locations marked in Fig. 4(b), have been installed over the past three decades and form two networks: the Central Weather Bureau Seismological Network (CWBSN; operated by the Seismological Observation Center of the CWB, Taiwan) and the Taiwan Telemetered Seismological Network (operated by the Institute of Earth Science, Academia Sinica, Taiwan). From this database, the events that occurred during the period from $1973 / 01 / 01$ to $2000 / 05 / 31$ are analyzed in this research. The total number of these events exceeds 200,000 and 58 of them have Richter-magnitudes $\left(M_{\mathrm{L}}\right)$ greater than or equal to 6.

Fig. 4(a) illustrates the distribution of the epicenters with $M_{\mathrm{L}}$ being equal to or greater than 3 . A 


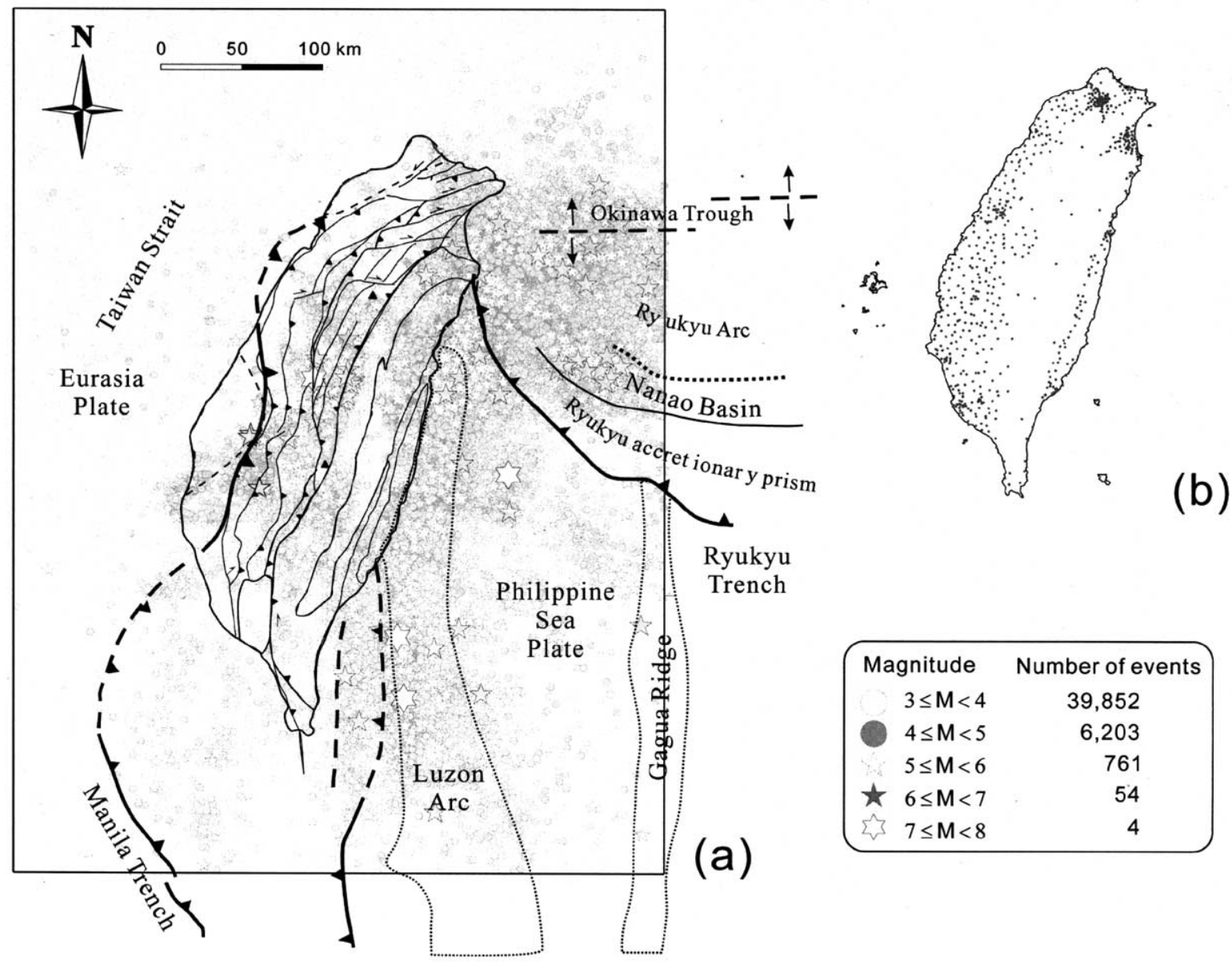

Fig. 4. (a) Distribution of epicenters within global Taiwan area. The geological structures are from Lallemand and Tsien (1997) and Lallemand et al. (2001). The epicenters plotted are from events, with magnitude equal to or greater than 3 on the Richter scale, which occurred during the period from $1973 / 01 / 02$ to $2000 / 05 / 31$. (b) The location of monitoring stations.

comparison of the distribution of epicenters (Fig. 4) with the geological structure of Taiwan (Fig. 2) reveals the close connection of the earthquake events with the neotectonic activity (e.g., plate subduction near the northeastern Taiwan and to the south of Taiwan) and the geological structure (e.g., a seismic zone adjacent to the east of the Peikang basement High).

Fig. 5(a) illustrates the statistics of the earthquake events, which have occurred in the vicinity of Taiwan during the observed period. A total of 208,617 events have been recorded and the epicenters of $81 \%$ events located with a margin of error equal to or smaller than $5 \mathrm{~km}$ for both horizontal and vertical planes (Tsai and $\mathrm{Wu}, 1997)$.
The magnitudes of earthquakes are estimated by three-component short-period digital seismographs with an error range of $M_{\mathrm{L}}=0.21$, which was obtained by jointly comparing the magnitudes measured from other systems (Shin, 1993; Wang et al., 1989; Wu et al., 2001).

Based on the analysis of seismic data in the Taiwan area by Shin (1993), the following relationship was adopted in converting earthquake magnitude to energy released:

$\log E=8.7+1.96 M_{\mathrm{L}}$

where $E$ is the seismic energy (erg). 
(a)

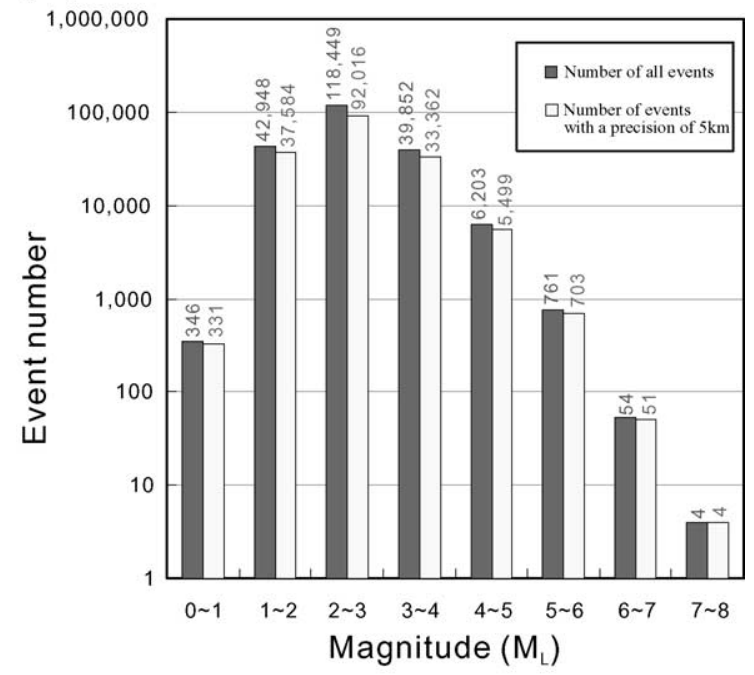

(b)

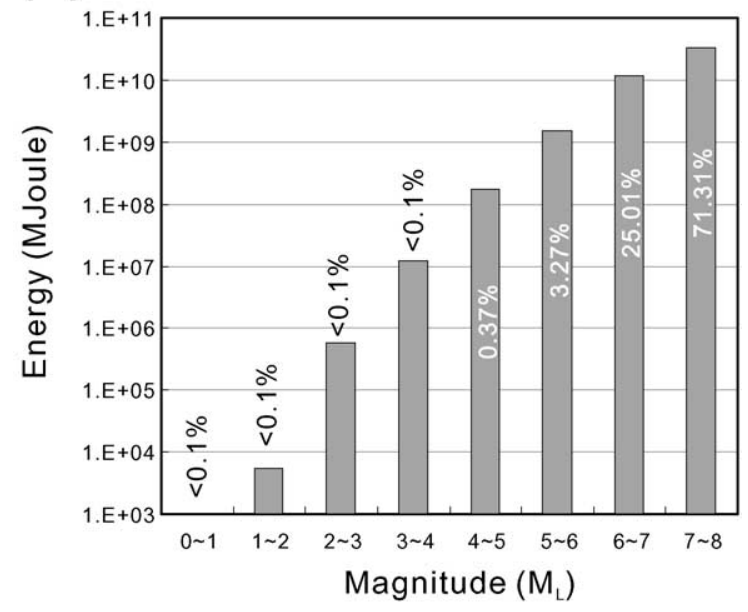

Fig. 5. Statistics of earthquakes which occurred from 1973 to 2000 in the Taiwan area. (a) Number of events of each magnitude and (b) corresponding seismic energy released from each magnitude. The percentage of seismic energy released from each magnitude to the total released energy is also indicated in (b).

In terms of seismic energy released, more than $96 \%$ of seismic energy was released in the form of strong earthquakes $\left(M_{\mathrm{L}} \geq 6\right)$. It seems that most of the seismic energy released is in the form of strong earthquakes where the global Taiwan is concerned. However, after detailed observation of the sub-areas of global Taiwan, it has been found that zones with different geological features exhibit different patterns, in the magnitude aspect and the time-variation aspect, of seismic energy release.

Studies on the focal mechanism of the major earthquakes around Taiwan have also been extensively conducted, which enables a more detailed understanding of the current fault movements or fractures and, accordingly, provides a clearer scenario regarding the current tectonic activities in this area (Kao and Chen, 2000; Kao and Rau, 1999; Kao et al., 1998a,b, 2000; Lin, 2000; Lin and Roecker, 1993; Pezzopane and Wesnousky, 1989; Rau et al., 1996; Wu, 1978; Wu et al., 1997; Yeh et al., 1991).

\subsection{Map of seismic energy}

Sometimes it is difficult to identify the characteristics in energy releasing of seismo-genetic zones, if simply by a map like Fig. 4. A map like Fig. 4 exhibits the following disadvantages.

(1) The more events, the more difficult in identifying seismic zones. The more events that are included, although such inclusiveness makes the map inherently more representative, the more difficult it is for the reader to identify which zone has more events. A total of 46,874 earthquakes with magnitudes ranging from 3 to 7 are crowded into Fig. 4, not to mention that another 161,743 events with magnitudes less than 3 have not yet been included in the same figure.

(2) The area where more events have occurred does not necessary represent more seismic energy released. It is difficult for readers to visually judge in which area more energy has been released.

Therefore, a method better presenting the distribution of seismic energy was proposed by Båth (1979, 1982), in which the energy of each event, calculated on the basis of a magnitude-energy relationship, is obtained first; the total sum of energy released from events located within a block (or a circle) is then determined by adding up the energy of each events. This total sum of energy within a block is then converted to a magnitude, designated as "cumulative magnitude" $\hat{M}_{\mathrm{L}}$ and ascribed to the center point of each block. Finally, a map of cumulative magnitude distribution can be obtained by moving the block over the area concerned. Such type of map has been applied to explore the relation of seismic energy distribution with tectonic structures (Muç o, 1998; Hollnack and Stangl, 1998). 
This method has the following characteristics (Båth, 1982): (1) it smoothes the discontinuous-point nature of the seismic events and converts the point-distribution to a regional distribution of released energy (the cumulative magnitude); (2) the variation of the selected energy indicator $\hat{M}_{\mathrm{L}}$ is neither too small nor too large in presenting the energy released through various magnitudes. Based on Båth's method, the cumulative magnitude map of Taiwan can be obtained as shown in Fig. 6, in which the total seismic energy within a circle of $5 \mathrm{~km}$ is ascribed to the center of the circle.

As seismic energy is a straightforward, quantitative measure indicating the impact of earthquakes, a map of seismic energy distribution was also obtained using an analogous technique as depicted in Fig. 6. To obtain Fig. 7, the total amount of seismic energy, converted from magnitude using Eq. (1), within a circle of $5 \mathrm{~km}$ in radius was assigned the center of the circle. As a greater circle may result in a greater total amount of energy, the total amount energy is then divided by the area of the circle to compensate for the influence of circle size. Therefore, the result yielded gives a unit of energy per area, which represents the regional distribution of "energy-releasing density".

In Fig. 6, greater cumulative magnitude is found along the subduction regions (to the northeast and to the south of Taiwan) and to the east of the Peikang basement High. Remarkably, the curved-belt pattern

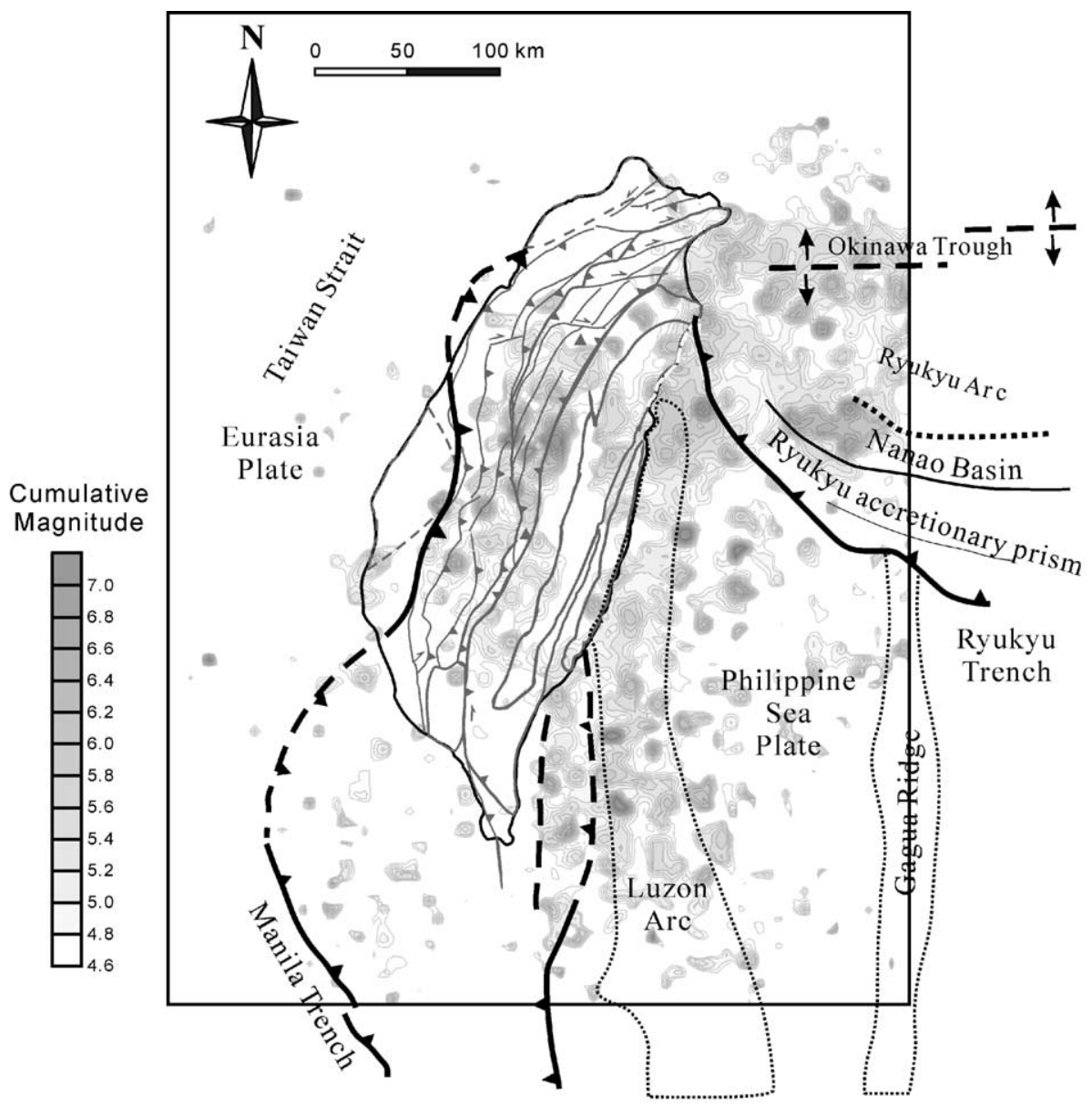

Fig. 6. Map of cumulative magnitude distribution over Taiwan. This map is constructed on the basis of a total of 169,550 events which occurred from 1973 to 2000 in Taiwan area, with errors of location less than or equal to $5 \mathrm{~km}$. The radius of the circle for computing cumulative energy is $5 \mathrm{~km}$. 


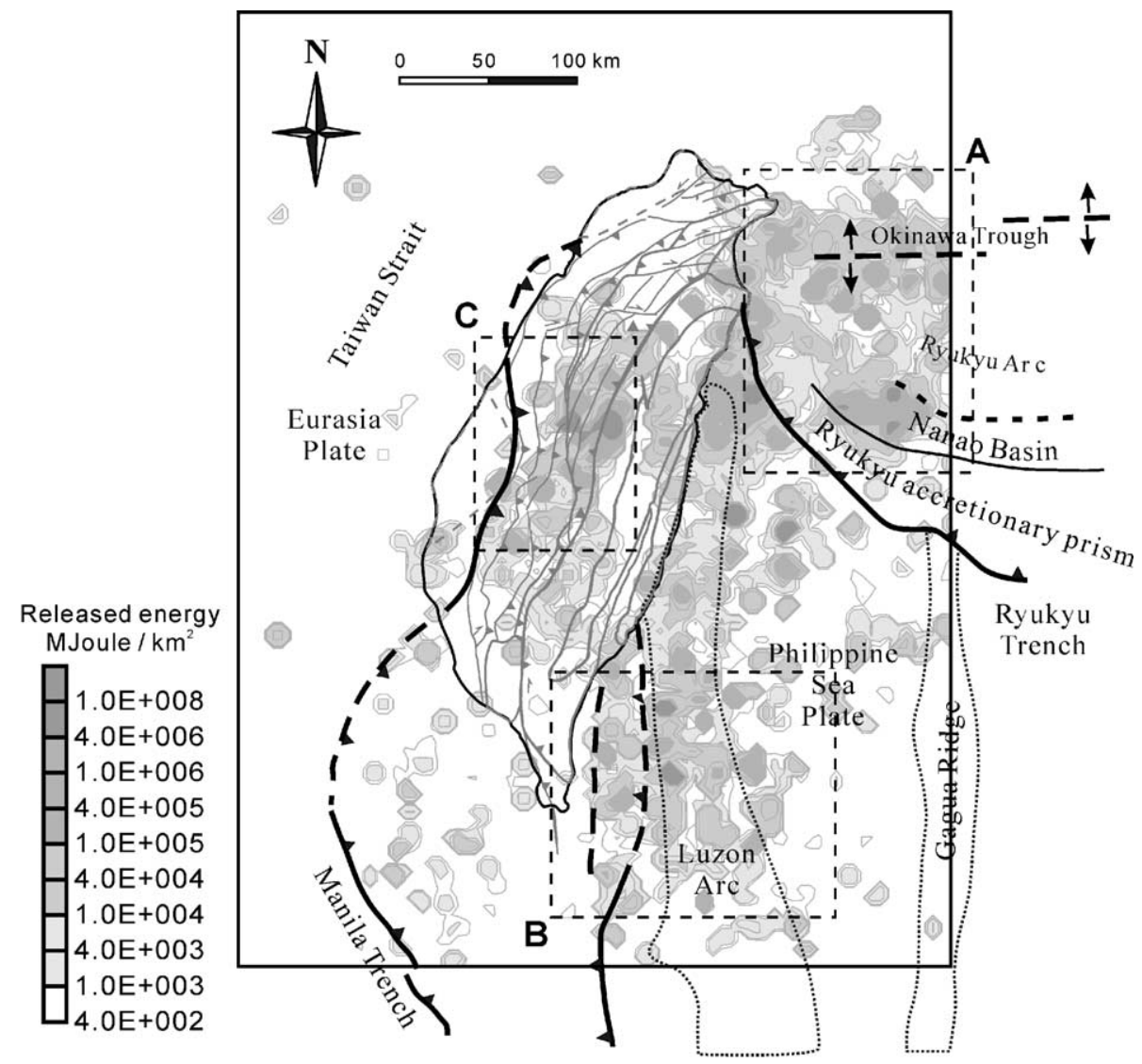

Fig. 7. Map of released seismic energy of Taiwan. This map is constructed on the basis of the same seismic data used in yielding Fig. 6. The radius of the circle for computing cumulative energy is $5 \mathrm{~km}$.

of seismic energy distribution in the proximity of Peikang basement High is consistent with the prediction by Jeng et al. (1996), by comparing Fig. 3 with Fig. 7. This reflects the close interconnection of seismic energy release with geological structure. On the other hand, such type of seismic energy map exhibits merits in quantifying seismic energy induced by a particular geological structure.

\section{Behavior of energy release}

Over the past 100 years, several major earthquakes have occurred in Taiwan and caused tremendous loss of lives and properties (Chang et al., 1998). In addition to those deep earthquakes from a subducted plate, the major earthquakes in the Western Foothills, which are onshore earthquakes, shallow in depth, resulting from continental collision or subduction, are devastating and, therefore, of concern. By comparing the seismic behavior, the distinct features of seismic energy releasing from different types of subduction are then highlighted.

\subsection{Selection of studied areas}

The contour of seismic energy shown by Fig. 7 provides a more accurate picture of where more energy has been released as compared with that shown by Fig. 4. Comparing Fig. 7 with Fig. 6, the major seismic zones indicated by these two figures are consistent. Based on Fig. 7 and the tectonic framework of Taiwan, three major seismic zones are selected for further observation. 
(1) A zone near northeastern Taiwan (marked by Box A in Fig. 7), where the Philippine Sea plate subducts the Eurasian plate. It is found that the focal depth in this region ranges from 1 to $300 \mathrm{~km}$ (cf. Figs. 8 and 13).

(2) A zone to the southeast of Taiwan (marked by Box $B$ in Fig. 7), which is the northern end of the Luzon arc, which is formed due to the subduction of the South China Sea crust under the Philippine Sea plate. The focal depth also ranges from 1 to $200 \mathrm{~km}$ (cf. Figs. 8 and 14) due to the subduction activity.

(3) A zone in middle Taiwan (marked by Box C in Fig. 7), which is part of the Western Foothills. In this zone, the surficial strata (with a thickness ranging from 5 to $20 \mathrm{~km}$, cf. Figs. 8 and 15) is compressed by the convergence of the Philippine Sea plate from the east and hindered by the Peikang basement High at the west. Consequently, a significant amount of

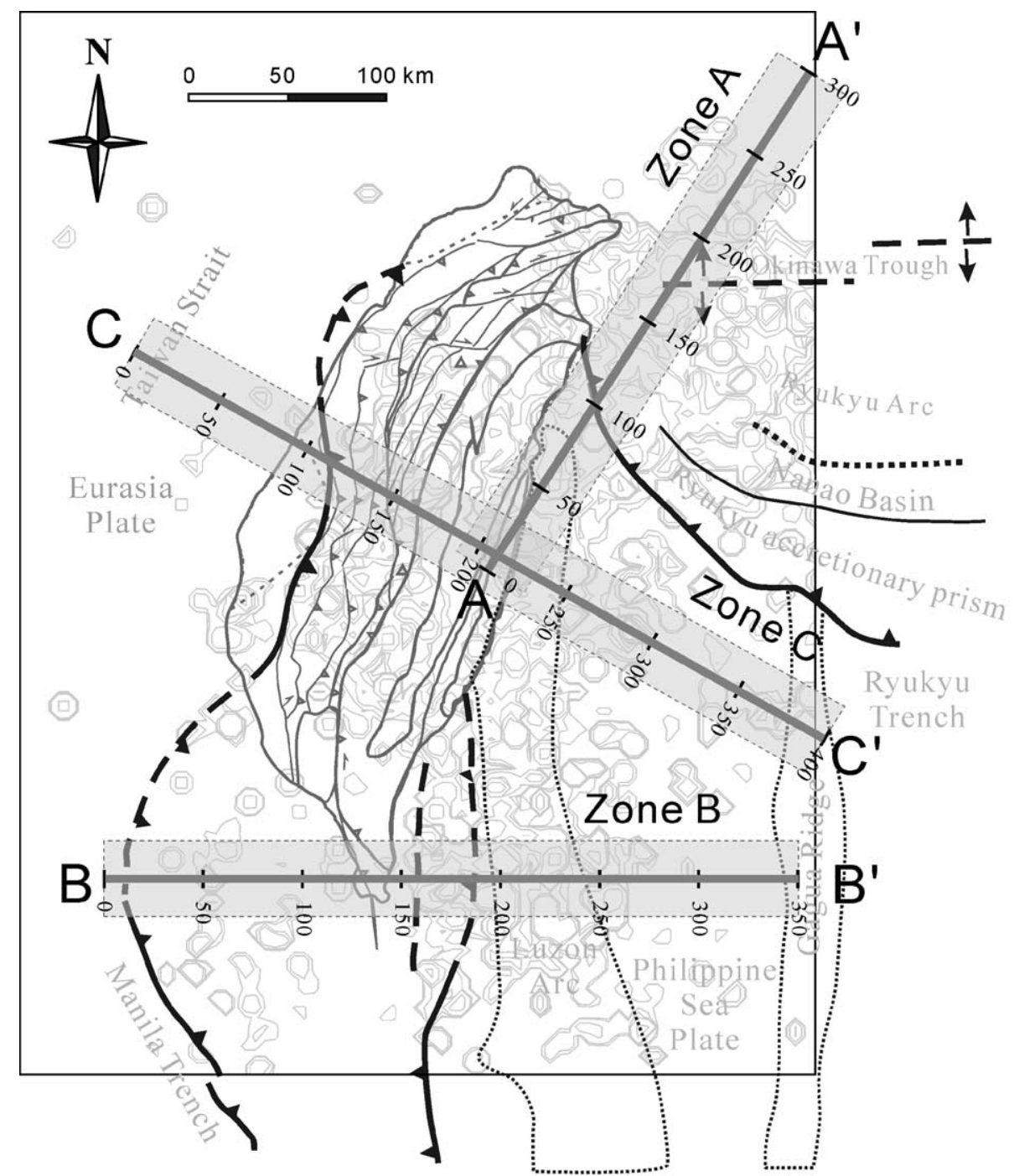

Fig. 8. Location of areas studied. Zones A, B and $\mathrm{C}$ are centered by the lines $\mathrm{AA}^{\prime}, \mathrm{BB}^{\prime}$ and $\mathrm{CC}^{\prime}$, with a width of $40 \mathrm{~km}$. The radius of the circle for computing cumulative energy is $5 \mathrm{~km}$. The length of each profile ( $\mathrm{unit}=\mathrm{km}$ ) is also marked in each line segment. 
energy is accumulated and eventually released. The focal depth in this region is less than $50 \mathrm{~km}$ (cf. Figs. 8 and 15) for almost all of the events.

In view of subduction being the major cause inducing seismic activity in Taiwan area, three zones, $\mathrm{A}, \mathrm{B}$ and $\mathrm{C}$ (centered by line segments $\mathrm{AA}^{\prime}, \mathrm{BB}^{\prime}$ and $\mathrm{CC}^{\prime}$ with a width of $40 \mathrm{~km}$ ) as indicated in Fig. 8 . Zones $\mathrm{A}$ and $\mathrm{B}$ have been identified as oceanic subduction (Lallemand, 2000) and Zone $\mathrm{C}$ has been identified as continental subduction (Lallemand, 2000) or as "collision without subduction" (Wu et al., 1997).

\subsection{Time variation of energy release}

To observe the release of energy along time, this research used a method similar to that used to produce the map of released energy. At a particular time, $t_{0}$, the total energy is calculated for the events occurring during $t_{0} \pm \Delta t / 2$ and ascribed to $t_{0}$. As a greater time interval used in determining total amounts of energy gives higher totals, dividing the total amount of energy by the time interval $(\Delta t)$ gives the "rate of energy release". Meanwhile, when comparison is made for different zones, an identical $\Delta t$ should be used for comparison purposes.

The time variations of rate of energy release for the three zones are shown in Fig. 9. In spite of the major earthquakes (e.g., $M_{\mathrm{L}} \geq 6$ or $E \geq 2.88 \times 10^{7} \mathrm{MJ}$ ), Zone A also has greatest amount of energy continuously released. It continuously releases energy at a rate of $1 \times 10^{6 \pm 1} \mathrm{MJ}$ per year, compared to the rates of $1 \times 10^{4 \pm 1}$ and $1 \times 10^{5}$ for Zones $\mathrm{B}$ and $\mathrm{C}$, respectively. In a long-term aspect (Wallace et al., 1984; Scholz, 1990; Sykes et al., 1999), this continuously release of seismic energy seems to represent a long-term "background noise" of a particular area. If so, Zone A appears to be the noisiest ground among the three zones. However, the noisiest ground is not necessary the ground which would release the greatest amount of energy. On the other hand, a seemly least noisy ground does not necessary represent an aseismic zone. Fig. 10 depicts the accumulation of seismic energy over time, namely the Benioff graph (Hamdache, 1998). It can be seen that Zone C, although is a quiet ground when compared to Zone A, has released the greatest amount of energy over the past three decades $\left(1.62 \times 10^{10} \mathrm{MJ}\right.$; Table 1$)$. Based on the
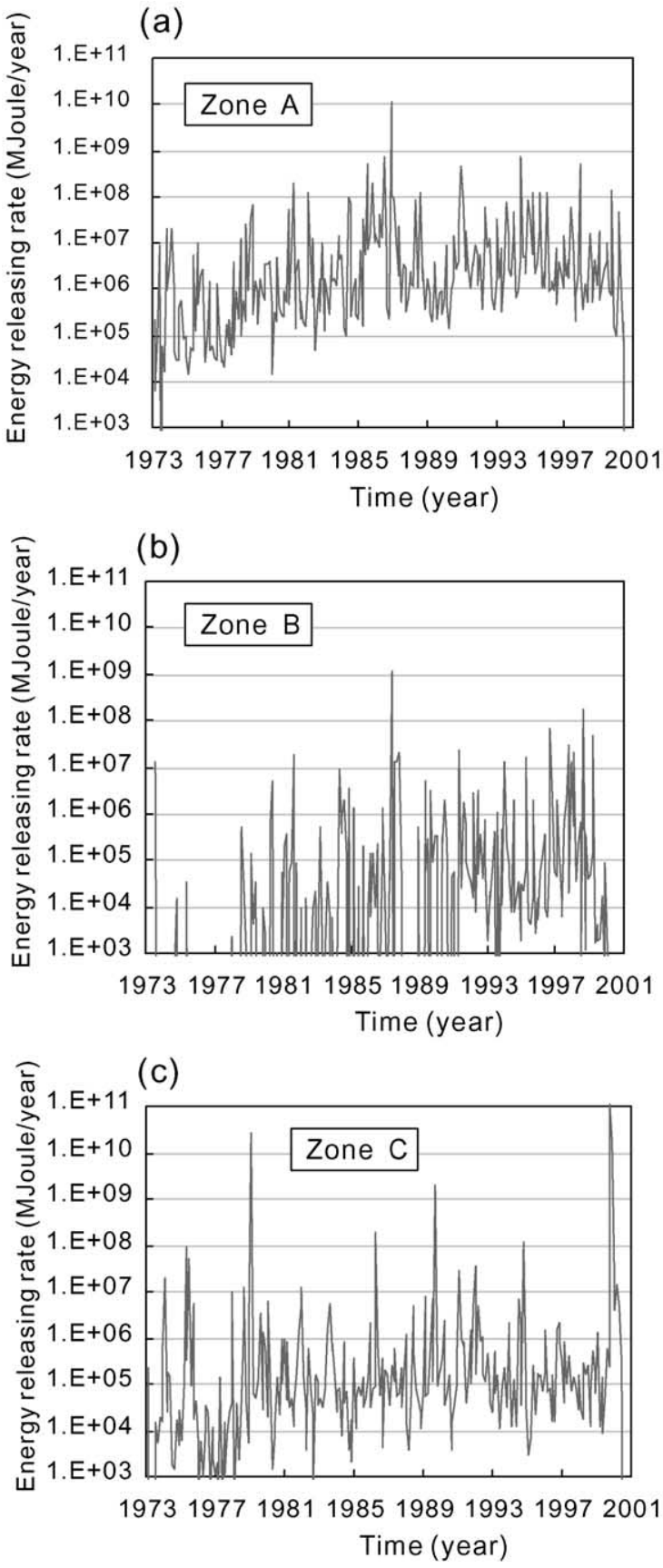

Fig. 9. Time variation of seismic energy released in the zones studied. The events recorded in Zones A, B and C are 57,464, 2178 and 11,909 , respectively. The time interval $(\Delta t)$ is 0.1 year. 
(a)

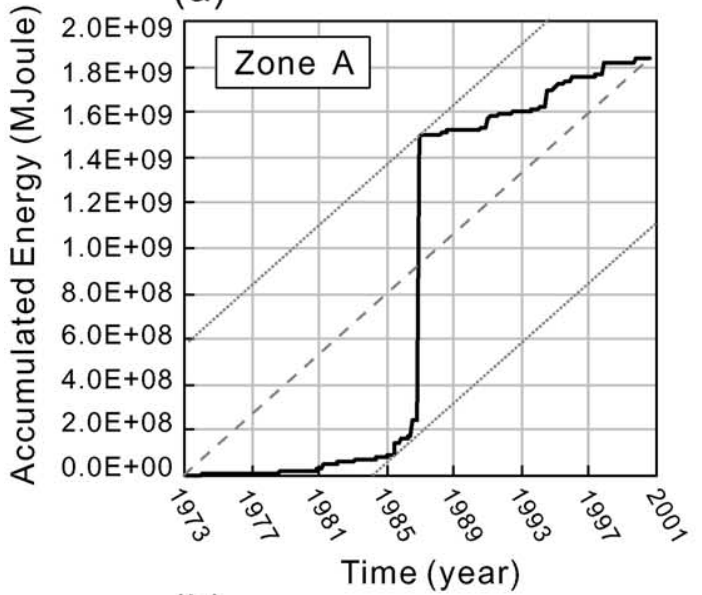

(b)
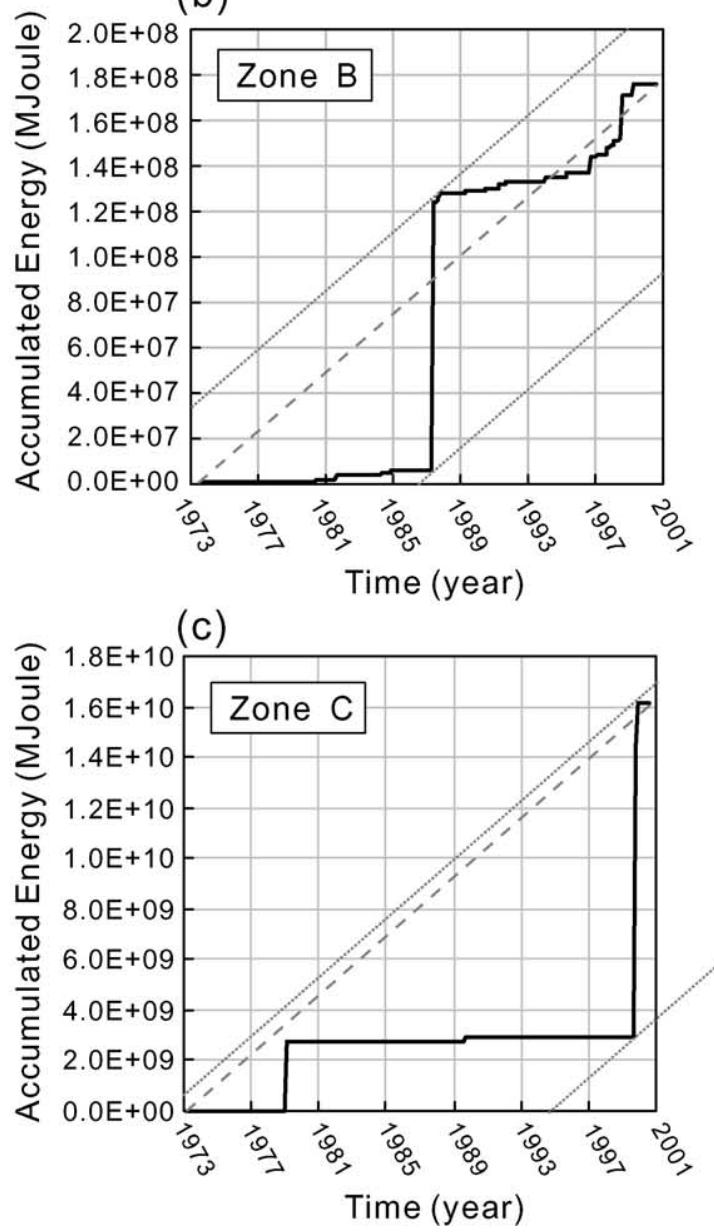

Fig. 10. The Benioff graph of the observed zones.
Table 1

Characteristics of energy release of the three studied zones

\begin{tabular}{llll}
\hline Characteristics & Zone A & Zone B & Zone C \\
\hline $\begin{array}{l}\text { Total energy } \\
\quad \text { released (MJ) }\end{array}$ & $1.84 \times 10^{9}$ & $1.76 \times 10^{8}$ & $1.62 \times 10^{10}$ \\
$M_{1}$ & 6.21 & 5.69 & 6.70 \\
$M_{\max }$ & 6.84 & 6.31 & 7.36 \\
$\quad \begin{array}{l}\text { Energy released from } \\
\quad\end{array}$ & $4.15 \times 10^{8}$ & $1.77 \times 10^{8}$ & $6.04 \times 10^{7}$ \\
$\quad \begin{array}{l}\text { Percentage of energy } \\
\quad \text { released from } M_{\mathrm{L}}<6\end{array}$ & $22.6 \%$ & $34.4 \%$ & $1.1 \%$ \\
$\quad$ & & & \\
\hline
\end{tabular}

(1) The period of observation is from $01 / 01 / 1973$ to $05 / 31 / 2000$

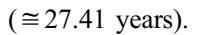

(2) All events, with a margin of error in locality greater than $5 \mathrm{~km}$ in either horizontal or vertical direction, are excluded.

Benioff graph, the mean annual energy release rate (expressed in terms of magnitude) and the maximum magnitude, which can possibly be released through one single event, can be obtained and expressed in terms of magnitude as $M_{1}$ and $M_{\max }$, respectively (Hamdache, 1998). As summarized in Table 1, Zone $\mathrm{C}$ tends to have a greatest mean annual energy release rate $\left(M_{1}=6.7\right)$ and the greatest variation of energy release $\left(M_{\max }=7.36\right)$.

\subsection{Release of energy over magnitudes}

As the total sum of released energy is calculated for the magnitudes ranging from 0 to $M$, this total energy increases as the upper bound $M$ increases. Fig. 11(a) shows the variation of accumulated energy over magnitudes for the three zones studied.

As far as small to medium earthquakes $\left(M_{\mathrm{L}}<6\right)$ are concerned, Zone A has the greatest amount of energy $\left(4.15 \times 10^{8} \mathrm{MJ}\right.$; Table 1$)$. This resulted from the fact that Zone A behaves as the "noisiest" ground among the three zones. Remarkably, although differed in the quantities of accumulated energy, the curves of the three zones are almost parallel to each other for magnitudes ranging from 3 to 5 (small to medium earthquakes). The pattern of background noise seems to be related to the interface friction (or roughness) of subducted plate, lithology, age of plate, velocity of convergence, etc., and requires further exploration (e.g., Kostoglodov and Ponce, 1994; Tanioka et al., 1997).

If the accumulated energy is further normalized by the total amount of released energy in each zone, the 

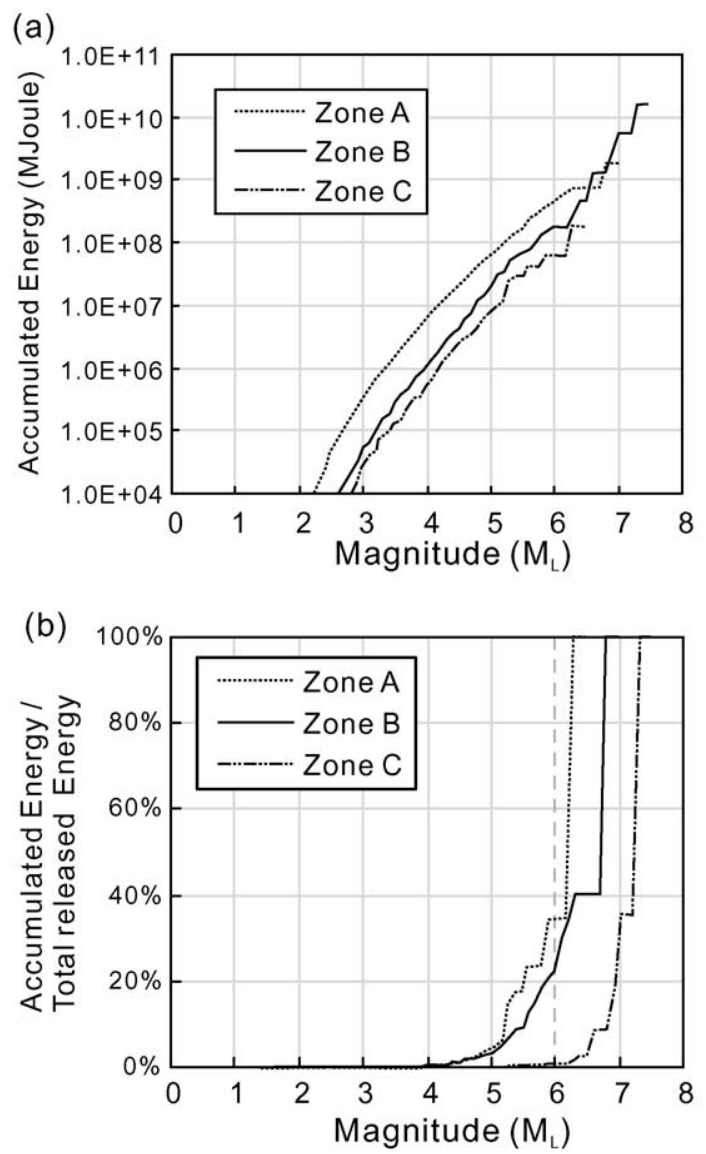

Fig. 11. Cumulation of released energy over magnitudes. The magnitude interval $(\Delta M)$ is 0.1 . The accumulated energy released by magnitudes ranging from 0 to $M_{\mathrm{L}}$ is shown in (a). The percentage of accumulated energy released by magnitudes ranging from 0 to $M_{\mathrm{L}}$ is shown in (b).

percentage of energy released through magnitude from 0 to $M$ can be obtained as illustrated in Fig. 11(b). It can be seen that, compared to the continental subduction zone, the oceanic subduction zones have a greater portion of energy released in the form of medium to small earthquakes $(22.6 \%$ and $34.4 \%$ of Zones $\mathrm{A}$ and $\mathrm{B}$, respectively, compared to $1 \%$ of Zone $\mathrm{C}$ ).

\subsection{Magnitude-energy-time relationship}

If both the magnitude and the time variation of energy releasing are taken into consideration, an energy-magnitude-time relationship can be obtained as shown in Fig. 12. To obtain Fig. 12, the energy
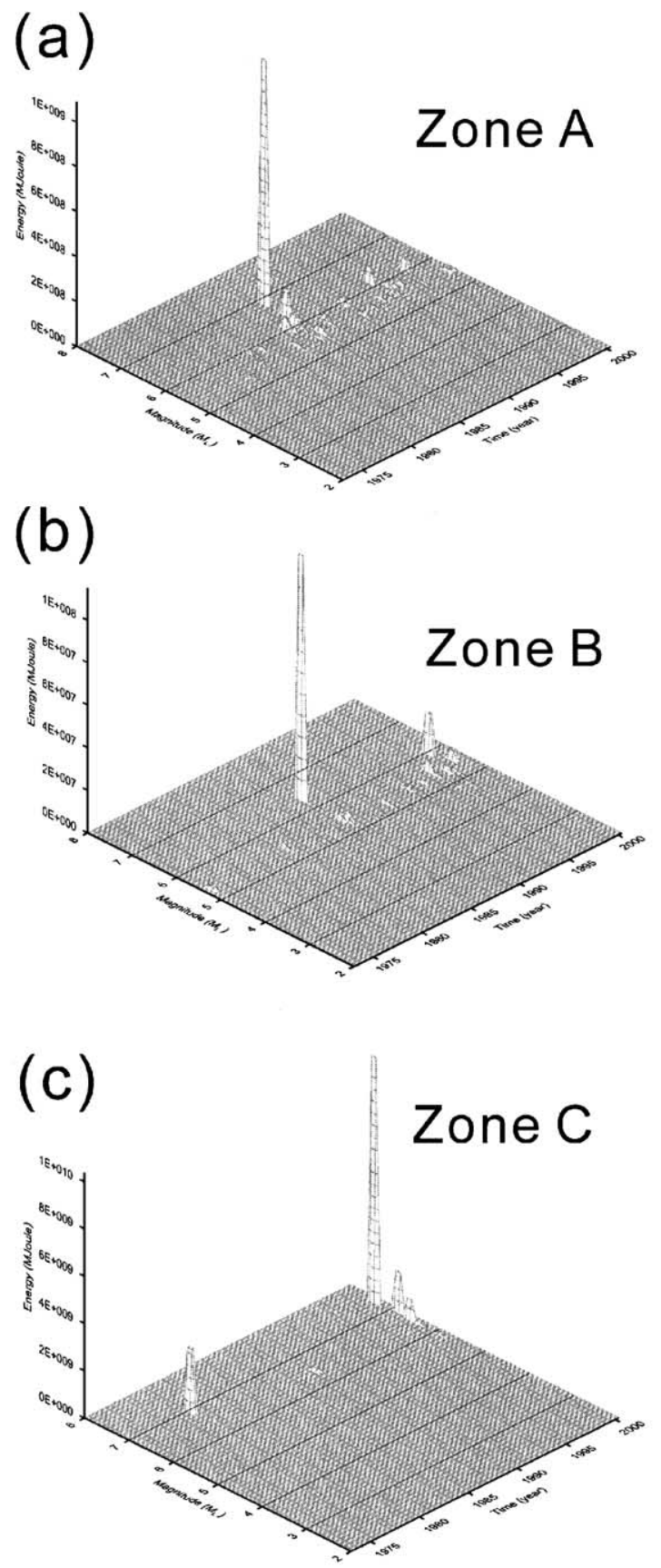

Fig. 12. Time variation of energy released at various magnitudes. The time and magnitude intervals $(\Delta t$ and $\Delta M$ ) are 0.1 year and 0.1 , respectively. 
released within a specific time interval $(\Delta T=0.1$ year $)$ and magnitude interval $(\Delta M=0.1$ in Richter scale) was obtained and plotted over magnitude and time span.

Fig. 12 elucidates the behavior of the energy release in terms of magnitudes over the time span. In a long-term point of view (Wallace et al., 1984), it can be seen that Zones A and B tend to release seismic energy from time to time, while Zone $\mathrm{C}$ tends to be quiet most of the time and then suddenly releases a huge amount of energy, which has been accumulated over a long period, in the form of a very strong earthquake. Remarkably, the minor peak adjacent to the major peak, shown in Fig. 12(c), is in fact the energy released through aftershocks of the Chi-Chi earthquake (Kao and Chen, 2000; Shin, 2000; Wang et al., 2000). This earthquake was the most devastating earthquake for the last five decades in Taiwan, with a death toll of 2505 human lives as well as causing collapse of 51,392 houses and buildings and the loss of US $\$ 12$ billion in property damage (Wang et al., 2000).

Based on the aforementioned observations, the characteristics of energy release can be identified as the follows.

(1) For the oceanic subduction zones, Zone A is much active than Zone B.

(2) Zone C, the continental collision zone with or without subduction, has generally released the greatest amount of energy and almost all of its energy is released in the form of a strong earthquake $\left(M_{\mathrm{L}} \geq 6\right)$. Zone $\mathrm{C}$ was quiet most of the time until a major shock with a magnitude of 7.3 occurred at 1999/09/21.

Overall, the seismological information collected in the last three decades indicates that a seemingly quiet zone is not necessarily less dangerous and could be more harmful than a zone which frequently releases seismic energy. A quiet zone, observed in a particular length of period, in fact represents either an aseismic zone or a zone waiting to release a major earthquake, which may often have a return period longer than the observational period. For the second case, this "quiet zone" in fact is a "seismic gap" and requires special attention (Kanamori, 1981). For instance, the area where Chi-Chi earthquake and its aftershocks occurred is the right area where concentration of strain energy is induced by neotectonic activity, according to existing analysis (Jeng et al., 1996; Lu, 1994; Lu and Malavieille, 1994). Therefore, an accurate judgment regarding whether a quiet zone is a seismic gap requires thorough understanding of the geological backgrounds and its features of energy release.

\section{Depth of earthquakes}

Further investigation seeking insight into the causes of the patterns of energy release may well pinpoint the important role of geological factors. A closer look into the profile of a particular subduction zone, which illustrates the seismic energy released in different local areas of this particular subducted zone, shall help us to distinguish the seismological behavior of the local areas.

The profiles of the released energy, the cumulative magnitude and location of earthquake events of Zones $\mathrm{A}, \mathrm{B}$ and $\mathrm{C}$ are shown in Figs. 13, 14 and 15, respectively. To obtain these profiles, the location of each event is first projected to the vertical plan centered at each zone, plan $\mathrm{AA}^{\prime}$ for Zone A, for example (Figs. 8 and 13(a)). On this vertical plan, the total energy of events located within a circle is calculated and ascribed to the center of the circle. Accordingly, contours of released energy and cumulative magnitude can be obtained (Fig. 13(b) and (c)) for a particular profile.

As can be seen from Figs. 13 and 14, the subducted plate is revealed by the hypocenter plots, energy contour and cumulative magnitude contour. While in Zone C, as depicted by Fig. 15, most events are located within the crust at a depth of less than 50 $\mathrm{km}$. Although some events occur at a depth greater than $50 \mathrm{~km}$, this kind of seismological data alone cannot indicate the existence of a subducted plate. On the other hand, if a breakout plate has fallen beneath the crust, this breakout seems to emit very little amount of seismic energy (Teng et al., 2000).

As far as the magnitude of earthquakes is concerned, the crust tends to release earthquakes in a wider range of magnitudes, including strong earthquakes, as shown in Fig. 16. The maximum magnitude of earthquake decreases with the increase of depth and especially, almost no earthquakes with $M_{\mathrm{L}} \geq 6$ could occur for depths greater than $50 \mathrm{~km}$. This phenomenon possibly resulted from the high 

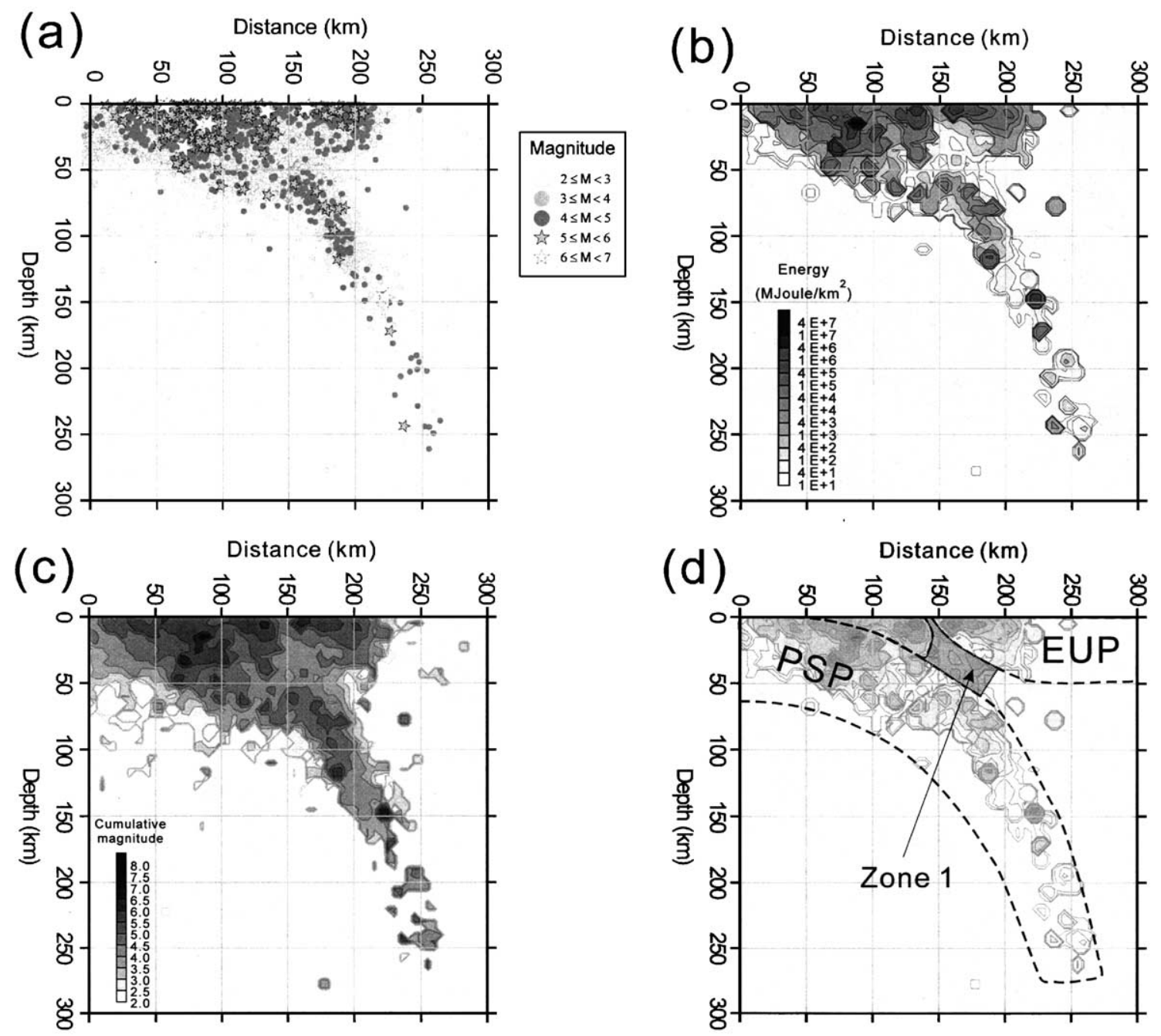

Fig. 13. The distribution of released energy and the cumulative magnitude over a vertical profile $\mathrm{AA}^{\prime}$ of Zone A. A total of 57,4643 events were recorded within the period from 1973 to 2000 with an error smaller than $5 \mathrm{~km}$. The intervals of distance and magnitude are $1 \mathrm{~km}$ and 0.1 , respectively. The distribution of hypocenters is shown in $(a) .(b-c)$ The distribution of the released energy and cumulative magnitude. A schematic illustration of the plates is shown in (d). Quiet Zone 1 is identified.

temperature and the high-confining pressure at a great depth since such environment enables ductile failure instead of brittle fracture, unlike the brittle fracture of the upper crust. If this phenomenon is representative, deep earthquake seems to be less hazardous for concerns in engineering aspects.

Remarkably, it is also found that lower limits of magnitude detected increased with depth as shown in Fig. 16. The increase in the distance traveled by a seismic wave from the focus to the monitoring station on the ground owing to a greater depth possibly accounts for the inability to detect events with small magnitudes. On the other hand, the ductile failure of the subducted plate decreases the possibility of triggering small magnitude earthquakes.

Near the crust of each zone, six "quiet zones" (or seismic gaps) exist, marked as Zones 1 to 6 in Figs. 13(d), 14(d) and 15(d). Whether such a quiet zone is 
(a)

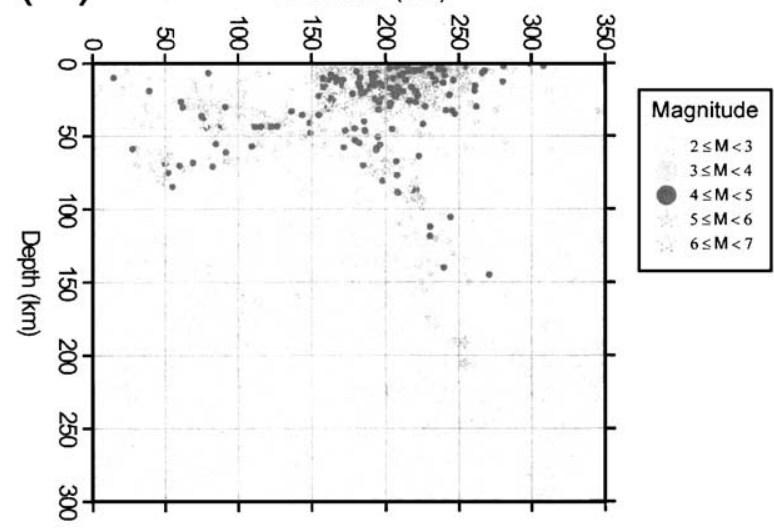

(c)

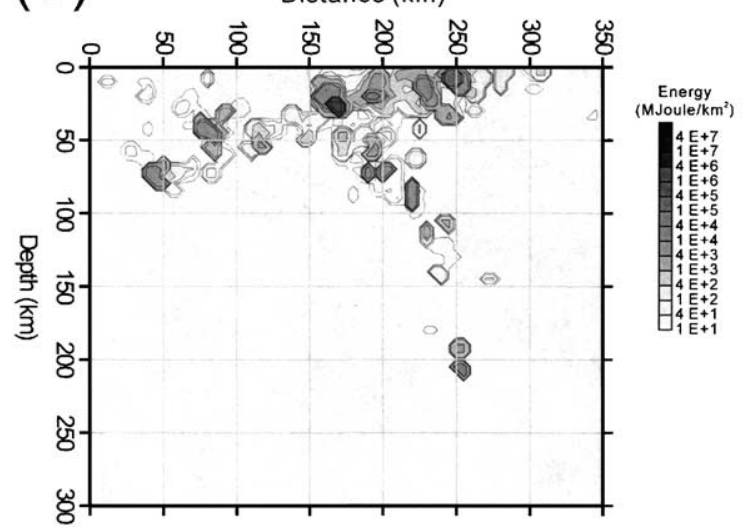

(b)

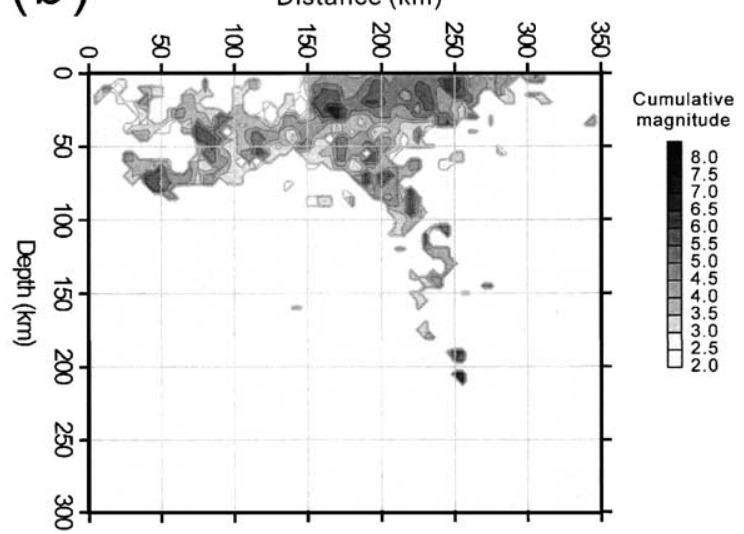

(d)

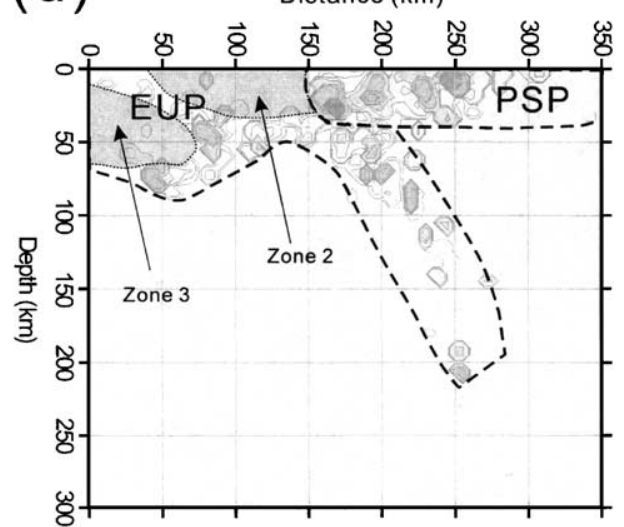

Fig. 14. The distribution of released energy and the cumulative magnitude over a vertical profile $\mathrm{BB}^{\prime}$ of Zone $\mathrm{B}$. A total of 2178 events were recorded within the period from 1973 to 2000 with a margin of error for location smaller than $5 \mathrm{~km}$. Two quiet zones, Zones 2 and 3 , are identified.

in fact an aseismic zone or a zone waiting to release a strong earthquake is a matter of concern. Table 2 summarizes current interpretations from other researchers or the author's speculation about the seismic activity of these quiet zones. These interpretations or speculations are based on the assumption that an accretionary prism is soft in nature and has less tendency to accumulate strain energy during the deformation process; while, on the other hand, brittle fracture can be developed within the upper crust and this can result in strong earthquakes (Byrne et al., 1988). Meanwhile, the bathymetric and geophysical data, including free-air gravity anomaly and seismic reflection profile, have been incorporated in reaching the interpretations (Deschamps et al., 1998; Jeng et al., 1996; Lallemand et al., 2001; Lallemand and Tsien, 1997; Lin, 2000; Lu, 1994; Lu and Malavieille, 1994).

\section{Limitations of the observational approach adopted}

\subsection{Sampling interval of time and magnitude}

All the methods of observation in this work (twodimensional energy contour, time variation of energy releasing, E-M curve as well as E-M-T or E-M-D 
(a)

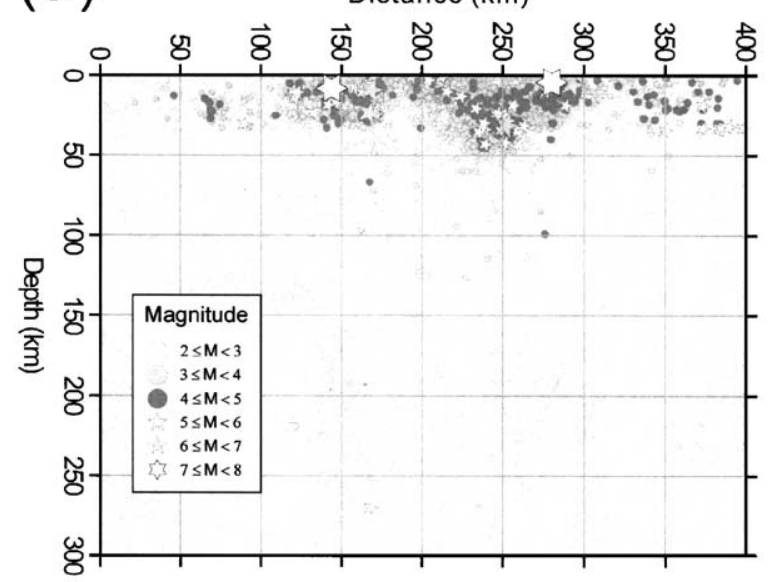

(c)

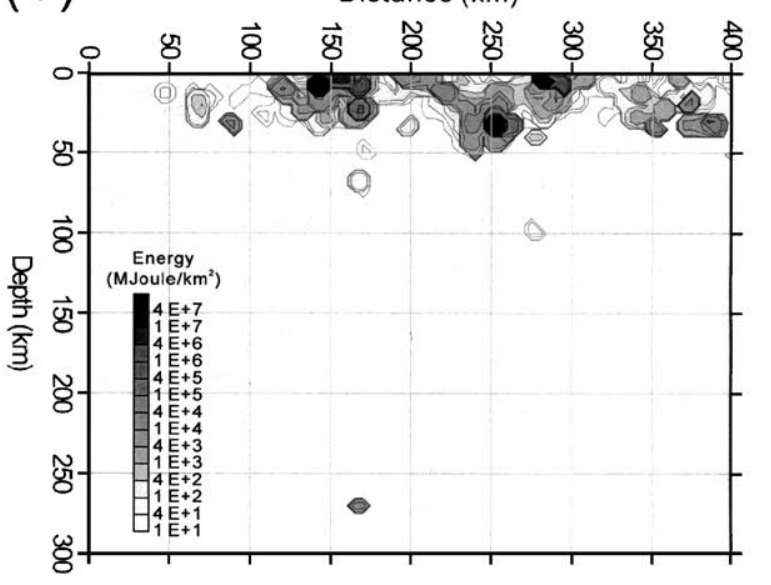

(b)

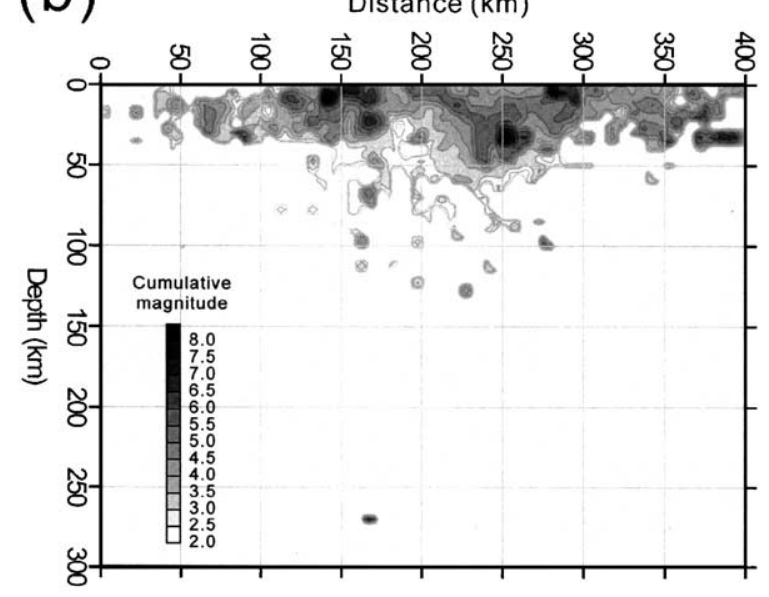

(d)

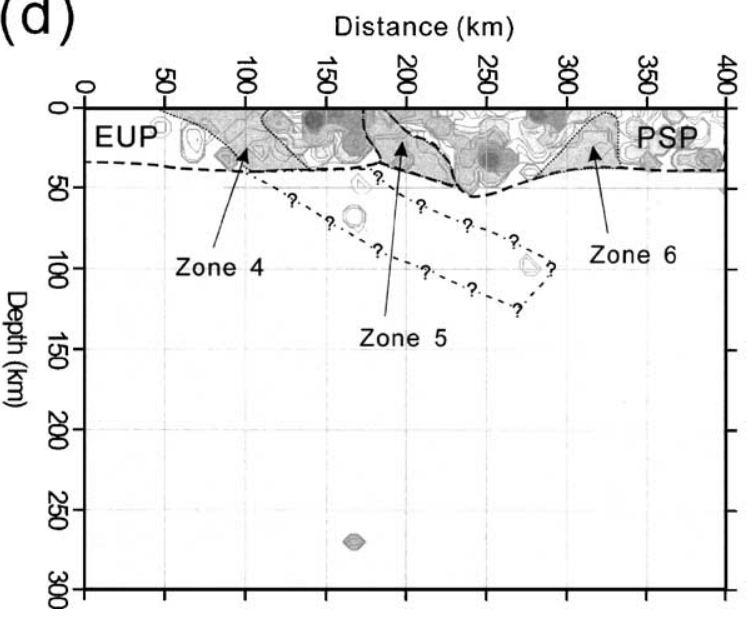

Fig. 15. The distribution of released energy and the cumulative magnitude over a vertical profile $\mathrm{CC}^{\prime}$ of Zone C. A total of 11,909 events were recorded within the period from 1973 to 2000 with a margin of error for location smaller than $5 \mathrm{~km}$. Three quiet zones, Zones 4 , 5 and 6 , are identified.

relations) are based on "moving-block (or circle)" method. The size of the intervals (time, magnitude, etc.) selected inherently affects the outcome of the plotting. In general, a smaller interval results in not only a smaller amount of total energy within the interval, but a "sharper" distribution also. The latter effect can be further demonstrated by considering a one-dimensional function, whose distribution is known, for instance, a normal distribution. Fig. 17 shows a comparison of computed distribution based on intervals of various sizes in comparison to the actual distribution. Assuming the actual distribution of events over $x$ is governed by a density function of normal distribution, which has the following form: $f(x)=\frac{1}{\sigma \sqrt{2 \pi}} \exp \left[-(x-\mu)^{2} / 2 \sigma^{2}\right]$; where $\mu=$ mean and $\sigma^{2}=$ variance. The mean and the variance of the actual function are selected as 0.0 and 0.4 , respectively, for the actual distribution shown in Fig. 17.

As shown in Fig. 17, as the interval of summing and averaging $f(x)$, namely the $\Delta x$, increases, the more wide-spreading the curve. Theoretically, the smaller the interval, the more representative the actual distribution is. However, an infinitely small interval would lead to a discrete distribution similar to the epicenter 


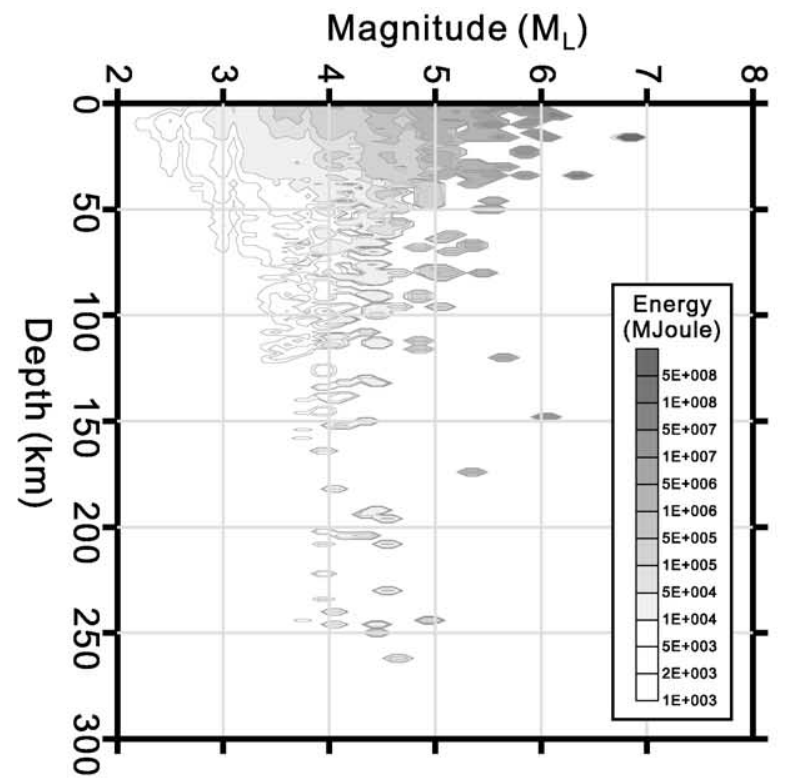

Zone A

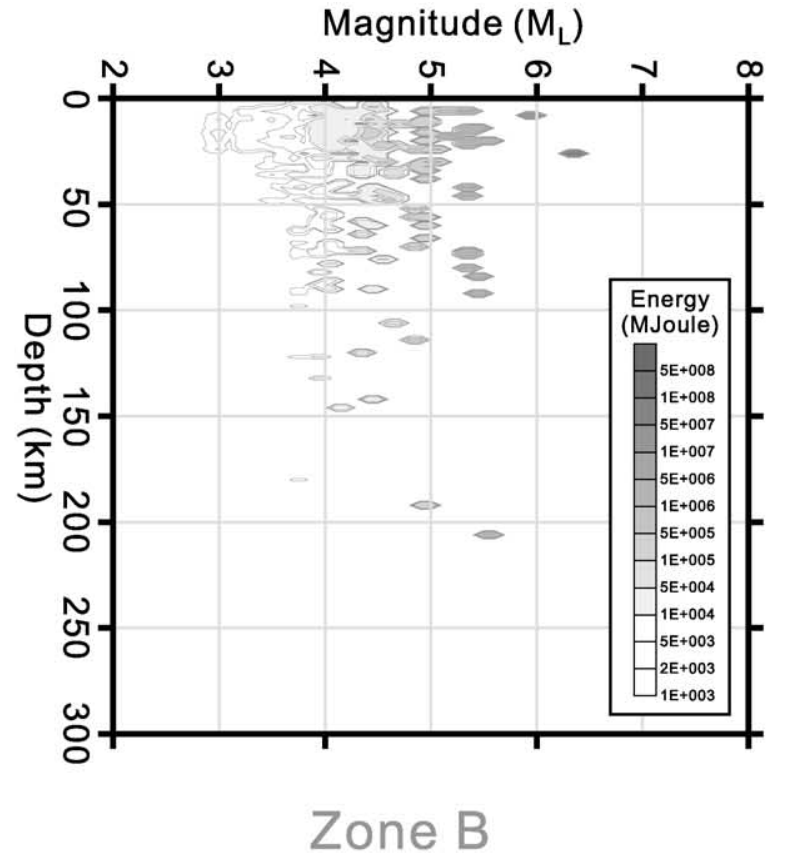

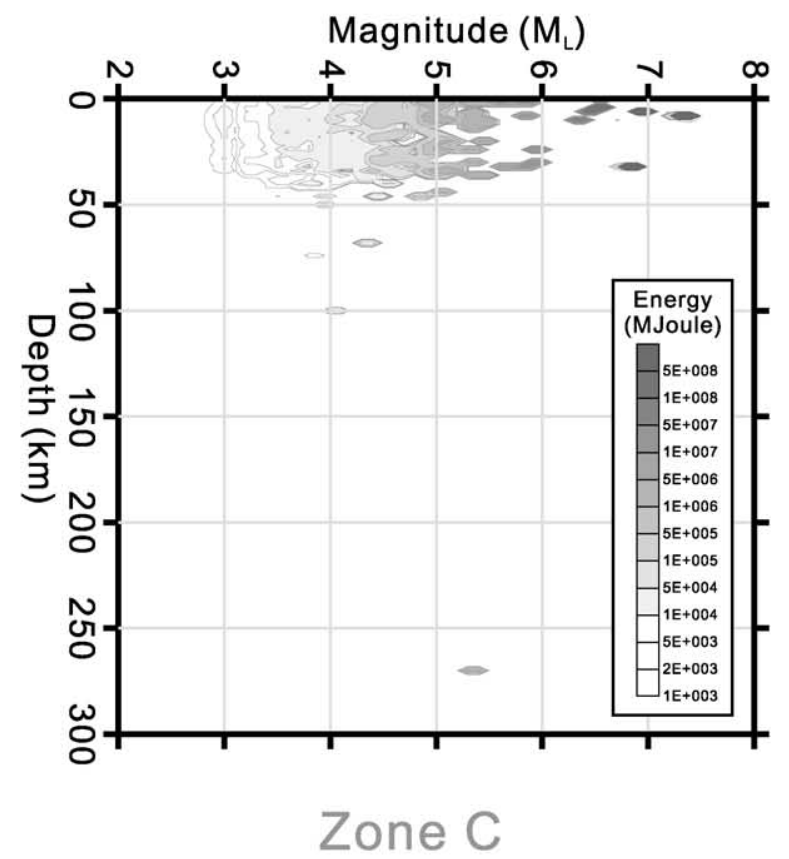

Fig. 16. The variation of "energy released from each magnitude" along with the depths for the three zones studied.

plot shown in Fig. 4. Therefore, an interval that is too small is not practically useful. As Taiwan's records show that the precision in locating an epicenter is usually within $5 \mathrm{~km}$, the smooth nature of the movingblock method more or less compensates for the uncertainty in the location of the epicenters. 
Table 2

The geological background and the possibility of the occurrence of strong earthquakes for quiet zones 1 to 6

\begin{tabular}{|c|c|c|c|}
\hline Quiet zone & $\begin{array}{l}\text { Geological } \\
\text { background }\end{array}$ & $\begin{array}{l}\text { Possibility } \\
\text { of strong } \\
\text { earthquake }\end{array}$ & Reference \\
\hline Zone 1 & $\begin{array}{l}\text { transported } \\
\text { accretionary } \\
\text { deposit }\end{array}$ & low & $\begin{array}{l}\text { Lallemand } \\
\text { et al., } 2001\end{array}$ \\
\hline Zone 2 & $\begin{array}{l}\text { accretionary } \\
\text { prism }\end{array}$ & low & $\begin{array}{l}\text { Lallemand and } \\
\text { Tsien, } 1997\end{array}$ \\
\hline Zone 3 & $\begin{array}{l}\text { deformation } \\
\text { front of thrust } \\
\text { faults }\end{array}$ & seemly high & $\begin{array}{l}\text { Lallemand } \\
\text { et al., 2001; } \\
\text { Lu and Malavieille, } \\
\text { 1994; Lu, } 1994\end{array}$ \\
\hline Zone 4 & $\begin{array}{l}\text { brittle fracture } \\
\text { of upper crust }\end{array}$ & high & $\begin{array}{l}\text { Jeng et al., 1996; } \\
\text { Lu, } 1994\end{array}$ \\
\hline Zone 5 & $\begin{array}{l}\text { continental } \\
\text { crust }\end{array}$ & low & Lin, 2000 \\
\hline Zone 6 & oceanic crust & seemly high & $\begin{array}{l}\text { Deschamps } \\
\text { et al., } 1998\end{array}$ \\
\hline
\end{tabular}

As to the time interval ( 0.1 year) and the magnitude interval (0.1), they are empirically determined on the basis of the numbers of events available. It should be noted that the intervals used for each plot should be explicitly stated, so that comparison can be made on a consistent basis.

\subsection{Length of observation period}

Yet another concern is raised, as the length of the observation period available in this work is about 30 years, which seems to be not long enough. In view of the fact that the return period of some strong earthquakes may exceed 100 years, this " 30 -year time window" can be too short for a definitive exploration of the actual energy-releasing behavior for a longer period or possibly, for earthquakes with greater magnitudes (e.g., greater than 8), and hence, the identified pattern may not be representative. Whether a 30 -year observation period should be considered as long-term or short-term depends on the magnitude and the return period of the maximum earthquake of concern. For engineering point of view, if the engineering structure is designed to resist earthquake with a magnitude less than 7 and the design life is 50 years, a 30 -year period of observation can be "long-term" according to the

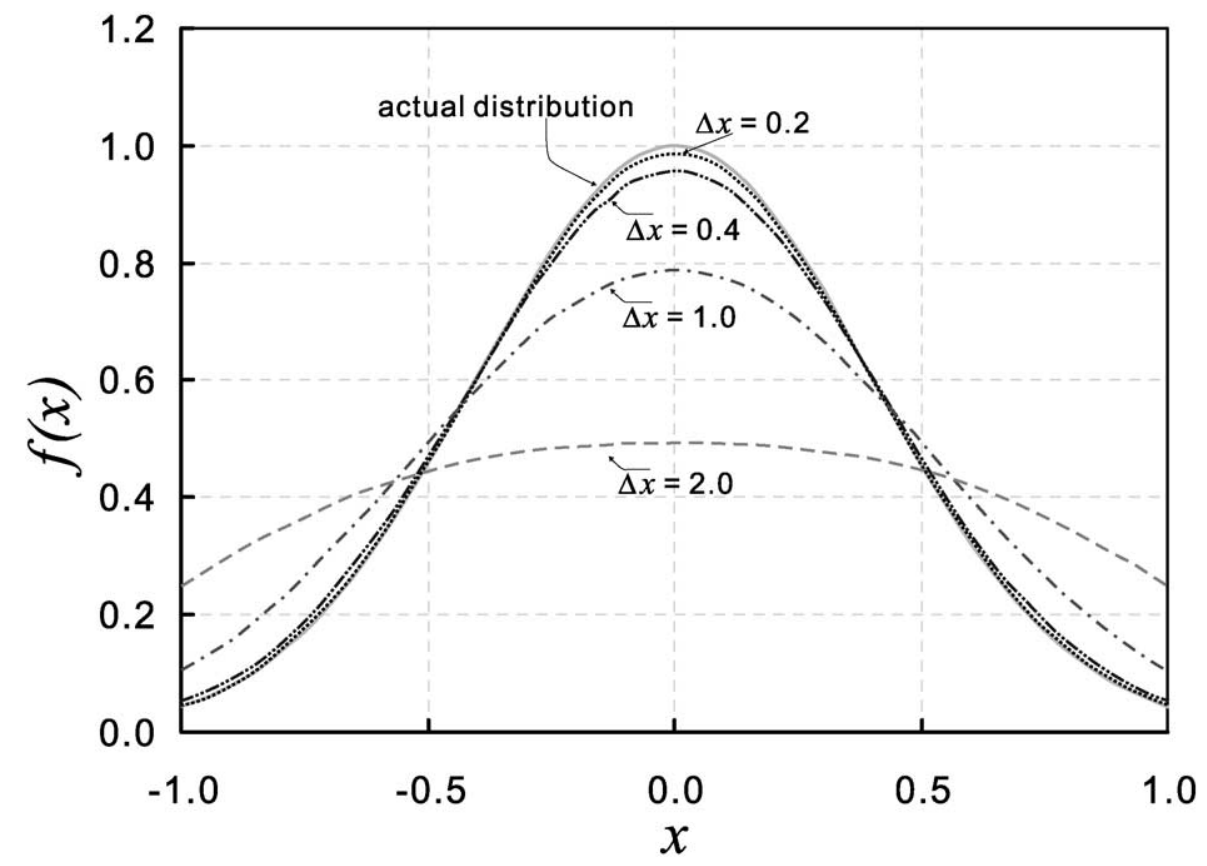

Fig. 17. Influence of interval size to the computed distribution. The function is the density function of normal distribution, which has the following form: $f(x)=\frac{1}{\sigma \sqrt{2 \pi}} \exp \left[-(x-\mu)^{2} / 2 \sigma^{2}\right]$; where $\mu=$ mean and $\sigma^{2}=$ variance. The mean and the variance of the actual function are selected as 0.0 and 0.4 , respectively, in this plot. $\Delta x$ is the range where the total density is calculated and averaged from the data of the actual distribution. 
definition by Wallace et al. (1984), Scholz (1990) and Sykes et al. (1999). However, if it is a nuclear waste repository, which is supposed to have a design life of hundreds of thousand years, a 30-year period of observation may not be sufficient.

Nevertheless, the behavior observed in a 30 -year period is the actual behavior, which has occurred. With a longer period of observation, the currently observed behavior can be further modified in so far as it differs from the longer-term behavior. Therefore, this research does not suggest extrapolating the observed behavior (in 30 years) to the behavior of a much longer period (e.g., hundreds of years) right away without support of further evidences. Meanwhile, however, the observed behavior within the frame of this time window does not necessary contradict and may not differ greatly from the reality of behavior of longer-term period. Indeed, concerns about the length of the time window should not prevent us from looking into the nature of energy release pattern and taking appropriate precautions.

\subsection{Seismic behavior and risk assessment}

Observations on the aspects of spatial distribution, time variation in the forms small, medium or strong earthquakes (expressed in term of magnitudes) of seismic energy releasing enable us to differentiate the seismic behavior of areas with different geological characteristics. This approach shows advantages in addition to the common used, probabilistic approachbased, $b$-value method (Krinitzsky, 1993, 1995; Hofmann, 1996) since it is capable of showing local seismic characteristics within a monitoring zone (e.g., seismic gap) and of providing direct energy measure. Meanwhile, the seismic behavior is characterized in terms of magnitude as well. Therefore, the joint use of this approach and the probabilistic approach will better serve the needs from engineering concerns, e.g., seismic zonation and design codes.

Similar to this proposed approach, the long-term seismic risk assessment conducted by Kanaori (2000) and Kanaori et al. (1991, 1992a,b, 1993) also focuses on the seismic energy release rate; the seismic gap and the relation of seismological behavior with the geological condition are emphasized as well, except that his analysis was based on historic major earthquakes instead of using earthquakes of all magnitudes measured by instruments.

Potentially, together with the techniques adopted in medium-term or even short-term analysis (Mogi, 1967, 1990; Scholz, 1990), assessment on what energy is yet to be released or what portion of stored energy has been released by one particular major earthquake can be possibly made provided that sufficient, accurately located seismic data recorded in a sufficiently long period is available. On the other hand, if regions with similar geological structure exhibit similar patterns of energy releasing, the pattern studied from regions, which have sufficient seismic data, can be applied to another region where the seismic data is not sufficient for a preliminary assessment.

\section{Conclusion and discussion}

An observational approach is adopted in this work to identify the energy-releasing behavior of different geological zones in Taiwan, including zones of oceanic subduction and continental collision or subduction. The proposed observational approach includes the following.

(1) Construction of an energy contour map-In conjunction with the geological map (Fig. 2) and the tectonic framework of Taiwan, three zones requiring observation can then be selected.

(2) Time variation of energy release-This aspect helps to determine whether the accumulated energy is occasionally relieved. The short-term pattern of seismic energy release can be compared to the long-term mean "energy release rate", and it is helpful in identifying possible quiescence, precursory clustering or even foreshocks (Kanamori, 1981; Mogi, 1967, 1990).

(3) Magnitude-Energy relationship-This aspect provides information about what portion of energy is released in terms of strong earthquakes.

(4) Magnitude-Energy-Time relationship-It provides the time variation and the associated magnitudes of energy release (e.g., Fig. 12). Background noises and aftershocks as well as their magnitudes of energy can be clearly seen from this type of plot.

(5) Energy-Depth relationship-This map is helpful in identifying the seismic pattern of differ- 
ent geological structures, e.g., the detailed structures within a subduction zone shown in Figs. 1315.

(6) Magnitude-Energy-Depth relationship-This provides the time variation of energy release and the associated magnitudes in relation to depth (e.g., Fig. 16). It shows that strong earthquake is less possible to happen in a deeply subducted plate (with depths greater than $50 \mathrm{~km}$ ).

(7) Several seismic gaps were identified, which specifies the areas where further study and evaluation are essentially needed to access the possibility of occurrence of strong earthquakes.

Accordingly, it has been found that the oceanic subduction tends to be noisier by continuously emitting small magnitude earthquakes, and to release energy from a wider range of depth owing to the existence of subducted plate. Unlike the deeply subducted plate (e.g., with depths greater than $100 \mathrm{~km}$ ), the surficial strata (with a depth of less than $50 \mathrm{~km}$ ) tend to release earthquakes in a wider range of magnitudes, including strong and devastating earthquakes.

The conventional seismic hazard map is often simply based on what have already happened in a region concerned. For instance, a seismic gap in the conventional map can be interpreted as a safe zone; however, this interpretation could be misleading since it could actually withhold a significant amount of energy waiting to be released. From the authors' point of view, an adequate seismic hazard map for engineering purposes should involve the tectonic and the geologic condition in proximity of the concerned area and their corresponding seismic energy release pattern as well.

\section{Acknowledgements}

The seismicity data used in this research is provided by Seismological Observation Center, Central Weather Bureau, Taiwan. The computer code was mainly developed by A. Chen. Special thanks are given to Dr. R.J. Rau and Dr. B.S. Huang, who have provided critical review and advices for this research. Meanwhile, the authors are grateful to the anonymous reviewer and $\mathrm{B}$. Muço, who have strengthened the technical soundness of this work.

\section{References}

Angelier, J., Barrier, E., Chu, H.T., 1986. Paleostress trajectories related to plate collision in the foothills fold-thrust belt of Taiwan. Tectonophysics 125, 161-178.

Båth, M., 1979. Introduction to Seismology. Birkhauser-Verlag, Basel, Switzerland, 428 pp.

Båth, M., 1982. Seismic energy mapping applied to Sweden. Tectonophysics $81,85-98$.

Biq, C., 1989. The Yushan-Hsuehshan megashear zone in Taiwan. Proceedings of the Geological Society of China 32, pp. 7-20.

Byrne, D.E, Davis, D.M., Sykes, L.R., 1988. Loci and maximum size of thrust earthquakes and the mechanics of the shallow region of subduction zones. Tectonics 7 (4), 833-857.

Chang, H.C., Lin, C.W., Chen, M.M., Lu, S.T., 1998. An Introduction to the Active Faults in Taiwan-Explanatory Text of the Active Fault Map of Taiwan. Central Geological Survey Special Publication, vol. 10. Taipei, Taiwan, 103 pp.

Deschamps, A.E., Lallemand, S.E., Collot, J.Y., 1998. A detailed study of the Gagua Ridge: a fracture zone uplifted during a plate reorganization in the mid-Eocene. Marine Geophysical Researches 20, 403-423.

Hamdache, M., 1998. Seismic hazard assessment for the main seismogenic zones in North Algeria. Pure and Applied Geophysics $152,281-314$.

Ho, C.S., 1986. A synthesis of the geological evolution of Taiwan. Tectonophysics $125,1-16$.

Hofmann, R.B., 1996. Individual faults can't produce a GutenbergRichter earthquake recurrence. Engineering Geology 43, 5-9.

Hollnack, D., Stangl, R., 1998. The seismicity related to the southern part of the Kenya Rift. Journal of African Earth Sciences 26 (3), 477-495.

Jeng, F.S., Hsiao, M.H., Lu, C.Y., 1996. Numerical simulation of neotectonics near Peikang high. Journal of the Geological Society of China 39 (4), 557-578.

Kanamori, M., 1981. The nature of seismicity patterns before large earthquakes. In: Simpson, D.W., Richards, P.G. (Eds.), Earthquake Prediction. Maurice Ewing Ser., 4. Am. Geophys. Union, Washington, DC, pp. 1-19.

Kanaori, Y., 2000. Seismic risk assessment of an active fault system: the example of the Tsurugawan-Isewan tectonic line. Engineering Geology 56, 109-123.

Kanaori, Y., Kawakami, S., Yairi, K., 1991. Space-time distribution patterns of destructive earthquakes in the inner belt of central Japan: activity intervals and locations of earthquakes. Engineering Geology 31, 209-230.

Kanaori, Y., Kawakami, S., Yairi, K., 1992a. Space-time distribution patterns of destructive earthquakes in the inner belt of central Japan (part2): moment-release rates and earthquakes prediction. Engineering Geology 32, 113-122.

Kanaori, Y., Kawakami, S., Yairi, K., 1992b. Space-time distribution patterns of destructive earthquakes in the inner belt of central Japan (part3): seismic hazard assessment. Engineering Geology 33, 99-110.

Kanaori, Y., Kawakami, S., Yairi, K., Hattori, T., 1993. Space-time correlation between inland earthquakes in central Japan and great offshore earthquakes along the Nankai trough: implication 
for destructive earthquake prediction. Engineering Geology 33, 289-303.

Kao, H., Chen, W.P., 2000. The Chi-Chi earthquake sequence: active, out-of-sequence thrust faulting in Taiwan. Science 288, 2346-2349.

Kao, H., Rau, R.-J., 1999. Detailed structures of the subducted Philippine Sea plate beneath northern Taiwan: a new type double seismic zone. Journal of Geophysical Research 104, $1015-$ 1033.

Kao, H., Jain, P.-R., Ma, K.-F., Huang, B.-S., 1998a. Moment-tensor inversion for offshore earthquakes east of Taiwan and their implications to regional collision. Geophysical Research Letters $25,3619-3622$.

Kao, H., Shen, S.J., Ma, K.-F., 1998b. Transition from oblique subduction to collision: earthquakes in the southernmost Ryukyu arc-Taiwan region. Journal of Geophysical Research 103, $7211-7229$.

Kao, H., Huang, G.-H., Liu, C.-S., 2000. Transition from oblique subduction to collision in the northern Luzon arc-Taiwan region: constrains from bathymetry and seismic observations. Journal of Geophysical Research 105, 3059-3079.

Kostoglodov, V., Ponce, L., 1994. Relation between subduction and seismicity in the Mexican part of the Middle America trench. Journal of Geophysical Research 99 (B1), 729-742.

Krinitzsky, E.L., 1993. Earthquake probability in engineering - part 2: earthquake recurrence and limitations of Gutenberg-Richter $b$-values for the engineering of critical structures. Engineering Geology 36, 1-52.

Krinitzsky, E.L., 1995. Deterministic versus probabilistic seismic hazard analysis for critical structures. Engineering Geology $40,1-7$.

Lallemand, S., 2000. Was the 1999 Chi-Chi earthquake in Taiwan a "subduction earthquake"? The Journal of Terrestrial, Atmospheric and Oceanic Sciences 11 (3), 709-720.

Lallemand, S., Tsien, H.H., 1997. An introduction to active collision in Taiwan. Tectonophysics 274, 1-4.

Lallemand, S., Font, Y., Bijwaard, H., Kao, H., 2001. New insights on 3-D plates interaction near Taiwan from tomography and tectonic implications. Tectonophysics 335, 229-253.

Lin, C.H., 2000. Thermal modeling of continental subduction and exhumation constrained by heat flow and seismicity in Taiwan. Tectonophysics 324, 189-201.

Lin, C.H., Roecker, S.W., 1993. Deep earthquakes beneath central Taiwan: mantle shearing in an arc-continent collision. Tectonics 12, 745-755.

Lu, C.Y., 1994. Neotectonics in the foreland thrust belt of Taiwan. Petroleum Geology of Taiwan 29, 1-26.

Lu, C.Y., Malavieille, J., 1994. Oblique convergence, indentation and rotation tectonics in the Taiwan mountain belt: insights from experimental modeling. Earth and Planetary Science Letters 121, 477-494.

Lu, C.Y., Angelier, J., Chu, H.T., Lee, J.C., 1995. Contractional, transcurrent, rotational and extensional tectonics: examples from northern Taiwan. Tectonophysics 246, 129-146.

Mogi, K., 1967. Earthquake and fractures. Tectonophysics 5, 3555.

Mogi, K., 1990. Seismicity before and after large shallow earth- quakes around the Japanese islands. Tectonophysics 175, 133.

Muço, B., 1998. Catalog of $M_{\mathrm{L}} \geq 3.0$ earthquakes in Albania from 1976 to 1995 and distribution of seismic energy released. Tectonophysics 292, 311-319.

Pezzopane, S.K., Wesnousky, S.G., 1989. Large earthquakes and crustal deformation near Taiwan. Journal of Geophysical Research 94, 7250-7264.

Rau, R.-J., Wu, F.T., Shin, T.-C., 1996. Regional network focal mechanism determination using $3 \mathrm{D}$ velocity model and $\mathrm{SH} / \mathrm{P}$ amplitude ratio. Bulletin of the Seismological Society of America $86,1270-1283$.

Scholz, C., 1990. The Mechanics of Earthquakes and Faulting. Cambridge Univ. Press, Cambridge, UK, 439 pp.

Seno, T., 1977. The instantaneous rotation vector of the Philippine Sea plate relative to the Eurasian plate. Tectonophysics 42, 209-226.

Shin, T.C., 1993. The calculation of local magnitude from the simulated Wood-Anderson seismograms of the short-period seismograms in Taiwan area. The Journal of Terrestrial, Atmospheric and Oceanic Sciences 4, 155-170.

Shin, T.C., 2000. Some seismological aspects of the 1999 Chi-Chi earthquake in Taiwan. The Journal of Terrestrial, Atmospheric and Oceanic Sciences 11, 555-566.

Suppe, J., 1984. Kinematics of arc-continent collision, flipping of subduction, and back-arc spreading near Taiwan. Memoirs of the Geological Society of China 6, 21-33.

Sykes, L.R., Shaw, B.E., Scholz, C.H., 1999. Rethinking earthquake prediction. Pure and Applied Geophysics 155, 207-232.

Tang, C.H., 1977. Late Miocene erosional unconformity on the subsurface Peikang high beneath the Chiayi-Yunlin coastal plain Taiwan. Memoirs of the Geological Society of China 2, $155-167$.

Tanioka, Y., Ruff, L., Satake, K., 1997. What controls the lateral variation of large earthquake occurrence along the Japan trench? The Island Arc 6, 261-266.

Teng, L.S., Lee, C.T., Tsai, Y.B., Hsiao, L.Y., 2000. Slab breakoff as a mechanism for flipping of subduction polarity. Geology 28, $155-158$.

Tsai, Y.B., Wu, H.H., 1997. A study of the errors in locating earthquake due to the geometry of the Taiwan seismic network. The Journal of Terrestrial, Atmospheric and Oceanic Sciences 8 (3), $355-370$.

Wallace, R.E., Davis, J.F., McNally, K.C., 1984. Terms for expressing earthquake potential, prediction, and probability. Bulletin of the Seismological Society of America 74 (5), 18191825.

Wang, C.Y., Shin, T.C., 1998. Illustrating 100 years of Taiwan seismicity. The Journal of Terrestrial, Atmospheric and Oceanic Sciences 9 (4), 589-614.

Wang, J.-H., Liu, C.-C., Tsai, Y.-B., 1989. Local magnitude determined from a simulated Wood-Anderson seismograph. Tectonophysics 166, 15-26.

Wang, C.Y., Chang, C.H., Yen, H.Y., 2000. An interpretation of the 1999 Chi-Chi earthquake in Taiwan based on the thin-skinned thrust model. The Journal of Terrestrial, Atmospheric and Oceanic Sciences 11, 609-630. 
Wu, F.T., 1978. Recent tectonics of Taiwan. Journal of Geophysical Research 26, 265-299, Suppl.

Wu, F.T., Rau, R.-J., Salzberg, D., 1997. Taiwan orogeny: thinskinned or lithospheric collision? Tectonophysics 274, 191220.

Wu, Y.-M., Shin, T.-C., Chang, C.-H., 2001. Near real-time map- ping of peak ground acceleration and peak ground velocity following a strong earthquake. Bulletin of the Seismological Society of America 91, 1218-1228.

Yeh, Y.-H., Barrier, E., Lin, C.-H., Angelier, J., 1991. Stress tensor analysis in the Taiwan area from focal mechanisms of earthquakes. Tectonophysics 200, 267-280. 